\title{
تقييم برنامج إعداد معلم اللغة الإنجليزية بكلية التربية بالرستاق من وجهة نظر طلاب التخصص
}

\author{
حمود بن عبدالله بن سالم الثكري \\ كلية التربية بالرستاق - سلطنة عُمان \\ humoud98.rus@cas.edu.om
}

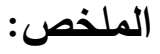

هدفت الدراسة إلى التعرف على تقييم برنامج إعداد معلم اللغة الإنجليزية في كلية التربية بالرستاق من وجهة نظر الطلبة، ولغرض جمع البيانات قام الباحث بإعداد أداة الدراسة المتمثلة في استبيان تقييم البرنامج، وقد تم التأكد من جودتها لجمع البيانات

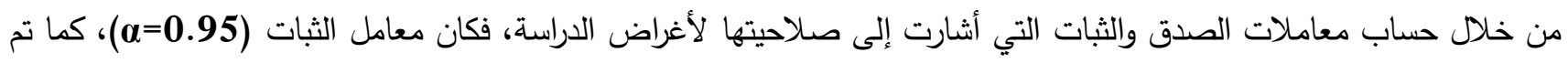
حساب الصدق العاملي للاستبيان. طبقت الدراسة على عينة من طلبة كلية التربية بالرستاق تخصص اللغة الإنجليزية في السنتين

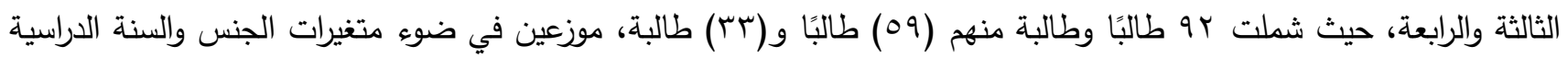
والمعدل التراكمي.

توصلت الدراسة إلى عدد من النتائج منها: إن تقييم الطلبة للبرنامج إعداد معلم اللغة الإنجليزية كانت بدرجة متوسطة حيث بلغ المتوسط العام لتقييم الطلبة للبرنامج (^) (ץ)، ومن حيث ترتيب المحاور جاء في المقدمة محور المقررات والساعات، ثم محور

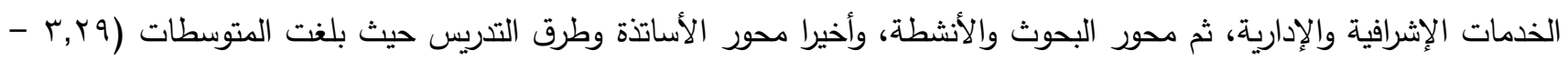

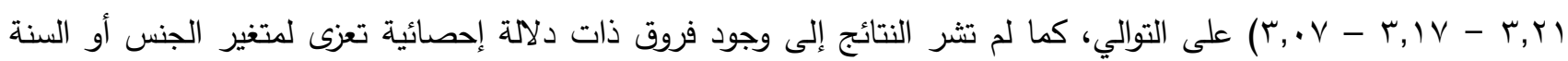

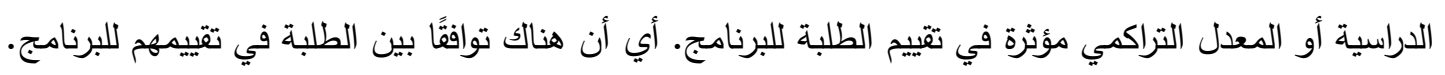
الكلمات المفتاحية: تقييم البرنامج، إعداد معلم اللغة الإنجليزية، كلية التربية بالرستاق. (c) 8 مقدمة الدراسة وإطارها النظري: تقوم المؤسسات الجامعية بدورًا كبيرًا في تحقيق التتمية الشاملة والمحافظة على مكتسباتها وإنجازاتها، ويمثل تطور التعليم

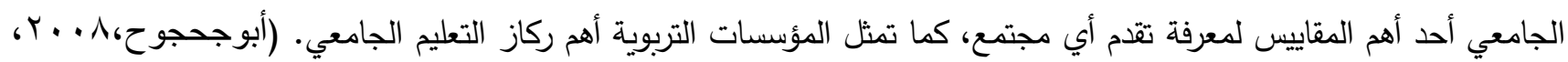

إن تطوير البرامج التعليمية هو الركيزة الأساسية لتطوير المؤسسات التعليمية؛ التي ترتكز على عملية التقويم. لذا فإن توفر

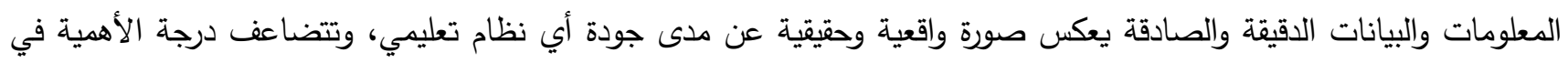

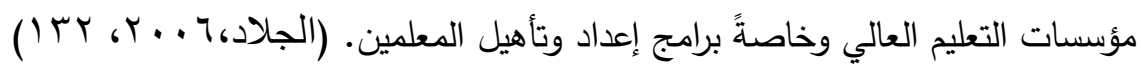


تمثل عملية إعداد وتأهيل المعلمين محورًا أساسيًا من سياسات واستراتيجيات التطوير التربوي لدى معظم دول العالم، فقد ركزت السياسات التربوية العالمية على اختلاف فلسفاتها وأهدافها ونظمها الاجتماعية والاقتصادية والسياسية على أهمية الارتقاء

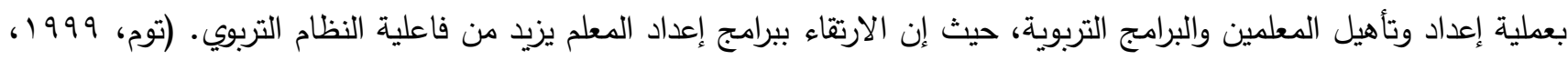

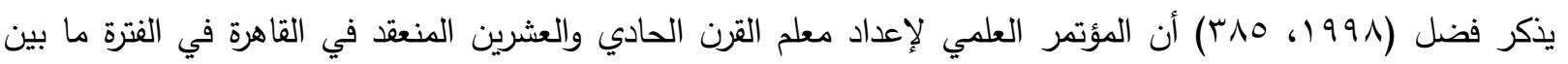

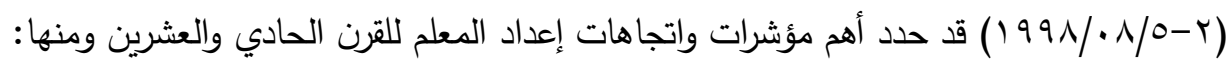

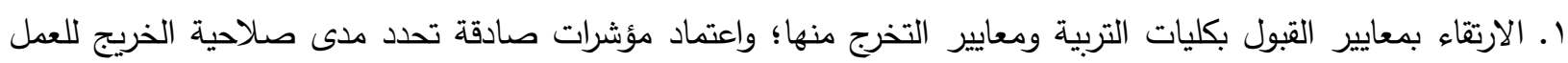
بمهنة التدريس. r. تطوير محتوى منهاج كليات التربية ونوعية المعرفة بحيث تسهم في تتمية الكفايات المهنية للمعلم التي تؤهله للحصول على بلى المعلومات واستخدامها وتوليدها بما يمكنه من اتخاذ القرار وتطوير قدراته ذاتيا. r. تأهيل قدرات المعلم التقنية ليكون قادرا على استخدام وتوظيف تقنيات المعلومات المتجددة في محاكاة الواقع التدريسي باستخدام برامج الحاسوب والإنترنت. لقد تطورت برامج إعداد المعلم؛ لمواكبة التطورات والتغيرات المتسارعة، حيث كانت برامج إعداد المعلم تركز على الجانب المعرفي من جوانب عملية إعداد المعلم؛ ولقد وجه كثير من الانتقادات لهذه البرامج حيث إن المعرفة لا تعني امتلاك المهارة

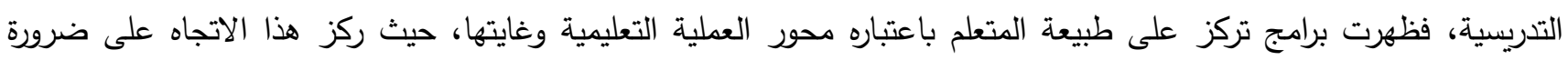
إكساب المعلم المهارات التي تمكنه من مساعدة المتعلم على تلبية احتياجاته المعرفية والوجدانية والاجتماعية والنفسية، وبعدها ظهرت برامج تركز على طبيعة المعلم ونمط شخصيته وأساليب تفكيره والدور الاجتماعي للمعلم لتمكنه من القيام بواجباته الاجتماعية

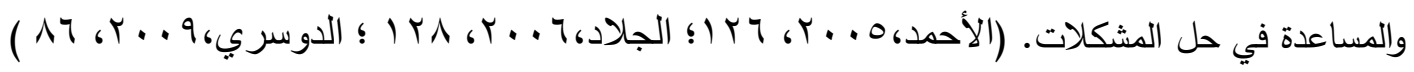
ظهرت البرامج التي تعتمد على تزويد المعلم بدراسة أكاديمية ومهنية وتخصصية من خلال مجموعة من المواد النظرية

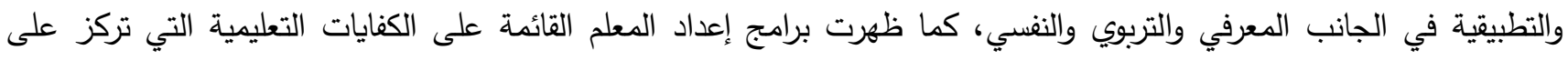

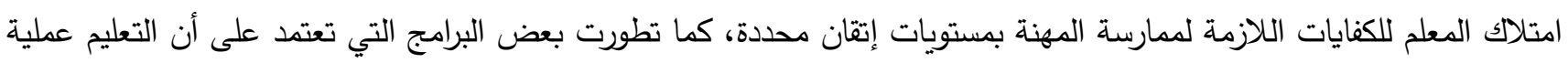
معقدة ومقيدة بالموقف التعليمي وظروفه؛ لذلك ركزت تلك البرامج على مهارات التفكير التأملي من خلال توظيف عمليات عقلية لتحديد الأهداف والأنشطة وإجراء التعديلات المطلوبة بحيث يحقق المعلم الأهداف المرجوة من خلال عمليات التحليل والنقد والتقييم.

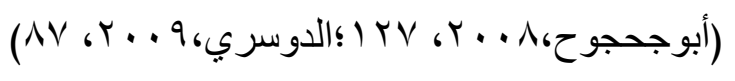

بالرغم من الاختلافات في اتجاهات إعداد المعلم إلا إنه يوجد اتفاق على ضرورة تضمين برامج إعداد المعلمين ثلاثة مجالات أساسية هي: الإعداد التخصصي الذي يركز على إتقان المعلم لمجال تخصصده، والجانب التربوي والنفسي الذي يركز على تتمية

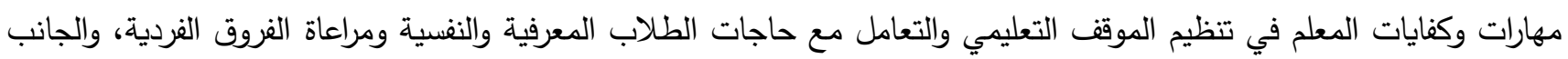

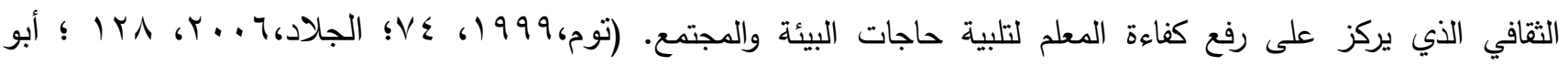

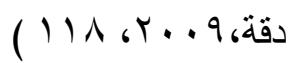

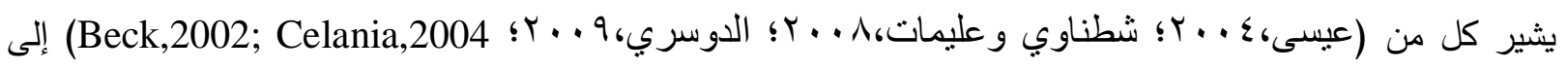
أن معلم القرن الحادي والعشرين يجب أن يكون قادرا على ممارسة الأدوار والمهام الجديدة الملقاة على عاتقه فهو خبير ومستشار وموجه ومشرف ومعلم وباحث قادر على التعامل مع التغيرات الاجتماعية والتطورات الحياتية، فالمعلم المنشود يجب أن يتئ يتسلح بالكثير من المهارات التي تجعله قادرا على مواكبة المستجدات المعرفية والتتنية وقادرا على التفاهم والتعامل والتعاون والعلاقات ولتهات الإنسانية بينه وبين زملائه وطلابه.

يؤدي التقويم دورًا مهما في تحسين وتطوير البرامج التعليمية؛ فهو الوسيلة التي نستشعر بها مدى تحقيق الأهداف المرجوة

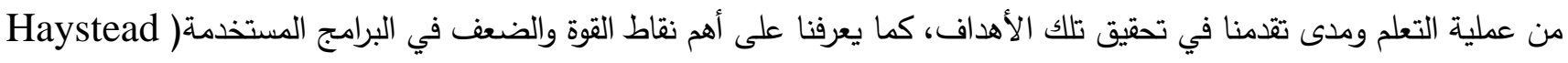


Marzano ,2010, 32 \& ) ). وللتقويم نماذج متعددة ولكل نموذج إيجابياته وسلبياته؛ وللمقوم الحرية في اختيار النموذج الذي يتلاءم مع الهدف من عملية التقويم التي يجريها، ويضيف أن هناك تصنيفات عدة ونماذج لتقويم البرامج منها: النموذج الكلاسيكي: يركز على التقويم في ضوء الأهداف، ومنها نموذج تايلر، نموذج الاعتماد: الذي يعتمد على دراسة العمليات التربوية وتقويم مخرجاتها ومنها نموذج ستك وسكرايفن، نموذج النظم: الذي يركز على النظام التربوي بكل عناصره من أهداف وعمليات ومخرجات ومنها نموذج ستيوفل بيم، نماذج التناقض: التي تركز على المعايير في مقارنة وتقييم ما يتم تحقيقه بناء على المعايير الأداء

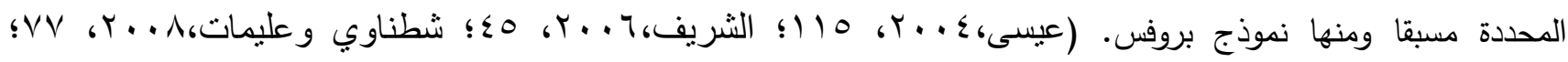

(McGreal,1988,103;

وفي السلطنة فإن كلية التربية تسهم في عملية التنمية المستدامة للمجتمع وتلبية احتياجاته من الكفاءات التخصصية في مجالات عدة منها مجال التعليم؛ من خلال برنامج إعداد معلم اللغة الإنجليزية، الذي بدأ تطبيقية في كليات التربية خلال الأعوام

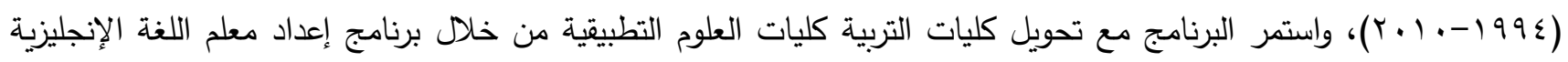

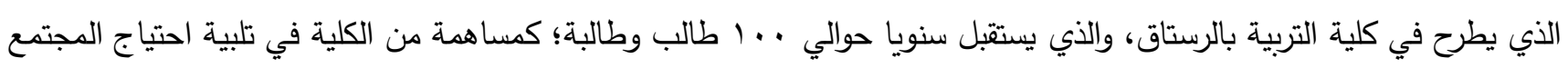
من هذا التخصص. لللك حاولت الدراسة تسليط الضوء على تقييم طلبة اللغة الإنجليزية بكلية التربية بالرستاق لبرنامج إعداد معلم اللغة

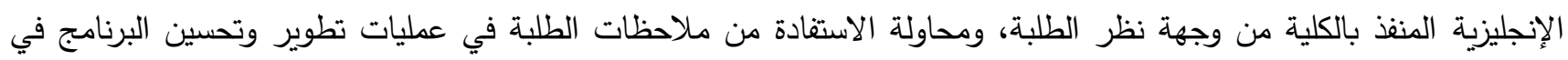
السنوات المقبلة.

مشكلة الاراسة:

تحتاج البرامج التعليمية عادة إلى عمليات تقويم مستمرة، تتكامل فيها المعلومات من مصادر متعددة، وكلما تعددت مصادر جمع المعلومات من مختلف العناصر ذات الصلة المباشرة وغير المباشرة بالبرنامج التعليمي كان القرار وإجراءات التحسين والتطوير أكثر واقعية وفاعلية. وتثير الدراسات السابقة إلى عدة مؤشرات مؤثرة في عملية التقويم منها: دراسة (Montgomery,2000) توصلت إلى أثر الثراتئ متغيرات الجنس والسنة الدراسية والتخصص في تقييم الطلبة لمدى استفادتهم الأكاديمية والتربوية من العلاقة بينهم وبين أساتذة

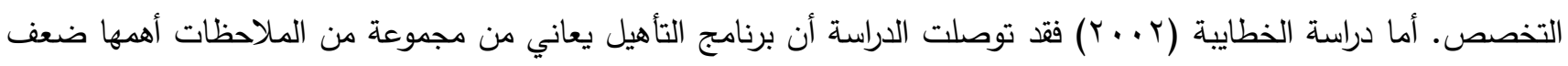

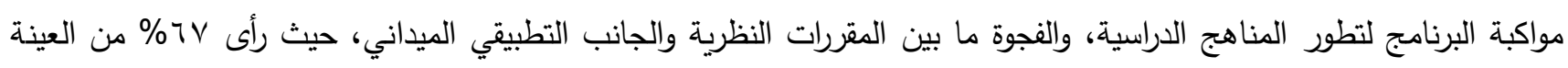

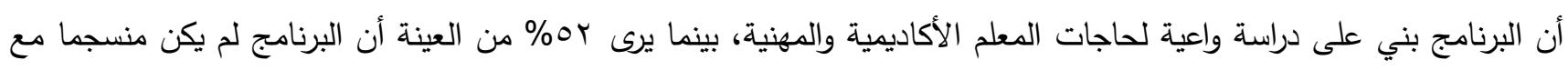

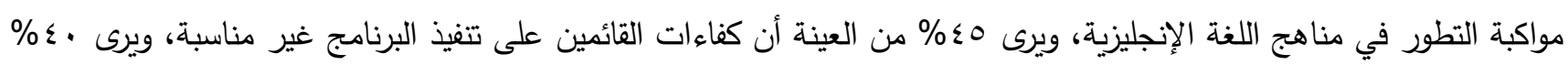

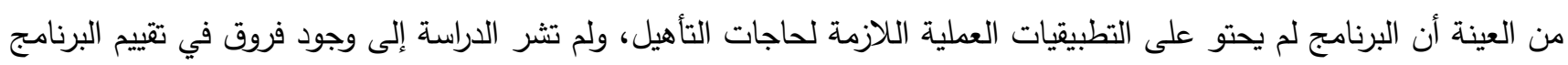
ترجع إلى متغيرات الجنس والسنة الدراسية والمعدل التراكمي.

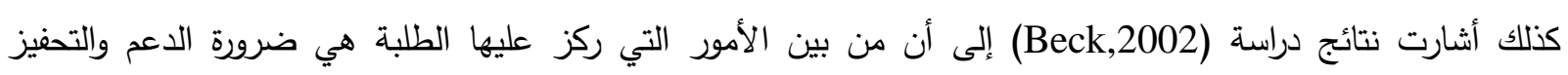

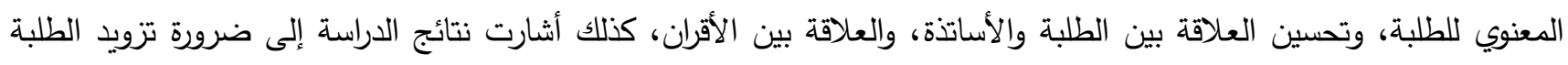

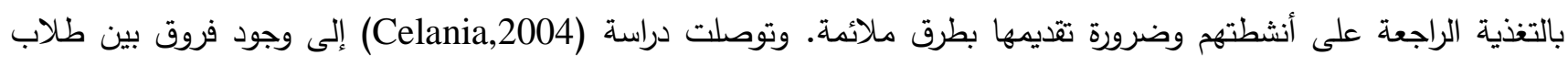

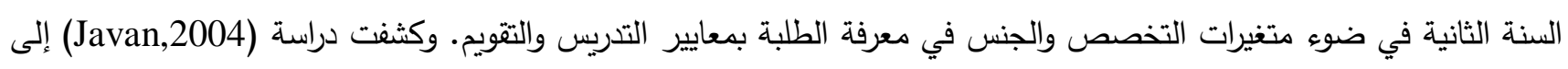

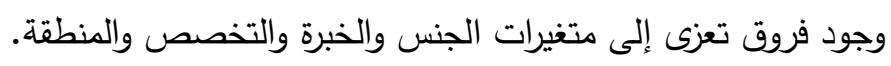

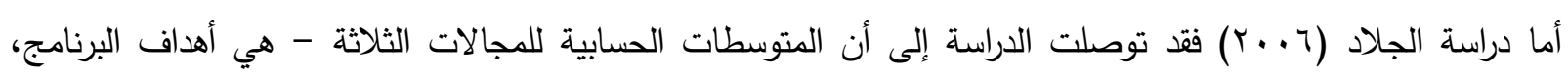
والمكون النظري، والمكون العملي - كانت عالية، حيث جاء المكون النظري في المرتبة الأولى ثم أهداف البرنامج، في حين جاء

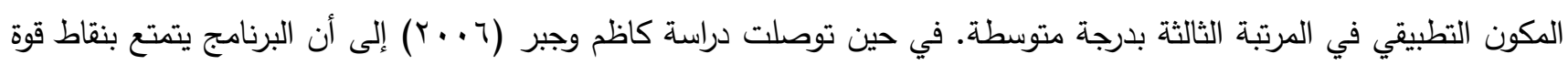


تتمثل في أهمية المقررات الدراسية، وأثارت النتائج إلى أن ؟ ؟\% من مقررات الخطة الدراسية متداخلة من حيث المضمون، كما

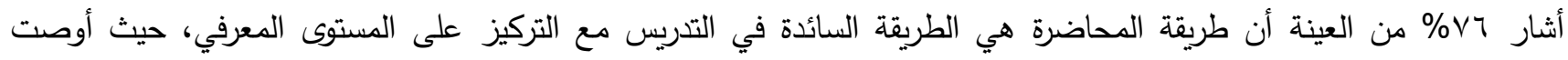
الدراسة بضرورة مراجعة البرنامج.

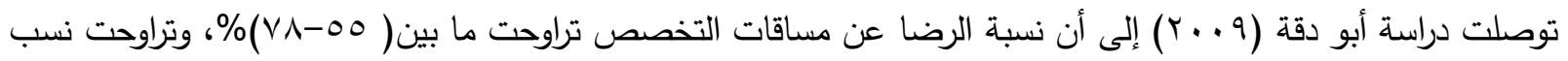

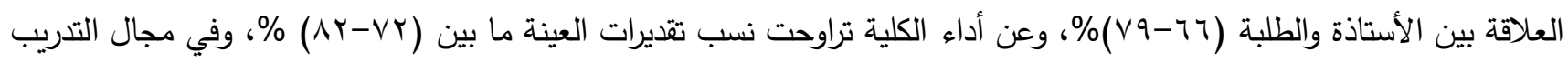

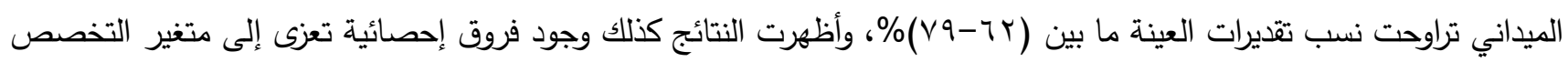
الأكاديمي لصالح الكليات التطبيقية مقارنة بالكليات الإنسانية في مجالات ألداء أداء الكلية ومساقات التخصص وعلات وعلاقة الطلبة بالأساتذة. وأشارت دراسة كل من (Mathes,2009; Vevere,2009) إلى أهمية تكاملية التقويم من عناصره المختلفة وركزت على أهمية الطلبة ودورهم في عمليات تثييم الجودة في المؤسسات الجامعية.

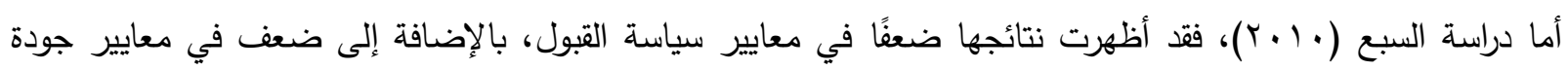

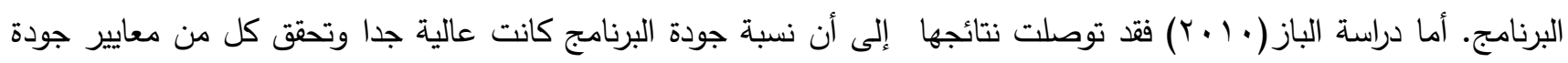
المحتوى وجودة الأهداف وجودة طرق التدريس. بينما أشارت دراسة (Haystead \& Marzano , 2010) إلى أثر دعم الأساتذة والمشرفين في عمليات التطوير والتقييم للمعلمين أثناء الخدمة. بينما أضافت دراسة (Saadi \& Saeed,2010) إلى أهمية وضوح

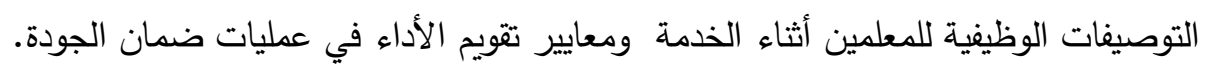

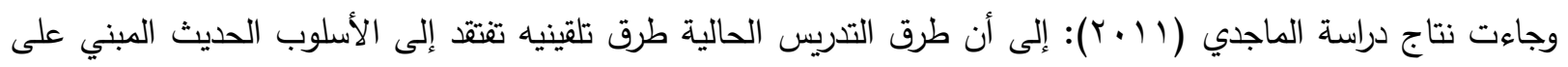
تتمية مهارات التقكير العلمي وحل المشكلات، وتحتاج برامج إعداد المعلم إلى مناهج دراسية خاصة بتوعية الطلاب بحقوقهم

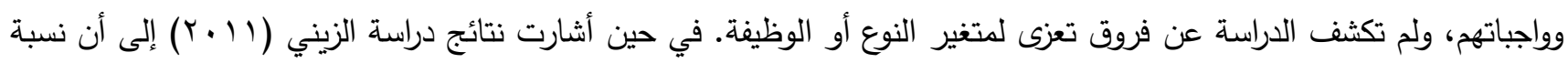

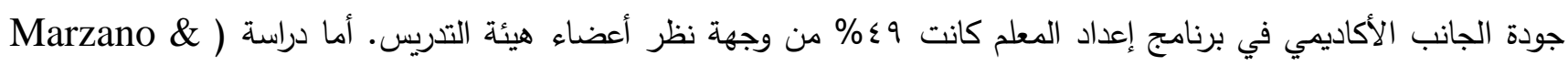

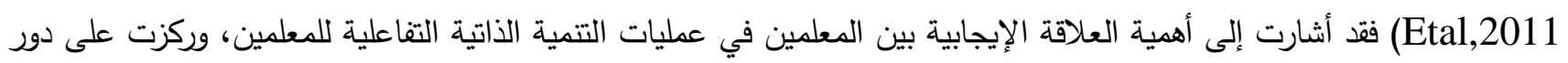
الدعم التفاعلي بينهم في عمليات التقييم والتطوير المستمر . توصلت نتائج دراسة الحميدي (Y Y • Y) إلى أن موافقة أفراد العينة على فاعلية البرنامج بالرغم من وجود فروق حول فاعلية المكون الثقافي والتخصصي. وتوصلت دراسة ( Hallman \& Meineke, 2016 إلى أن برامج إعداد المعلمين لا تزال بحاجة

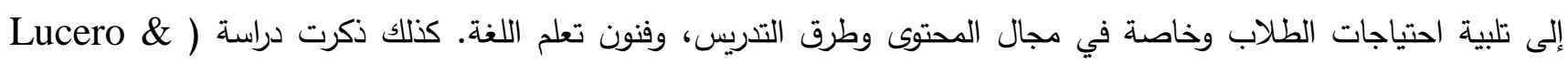

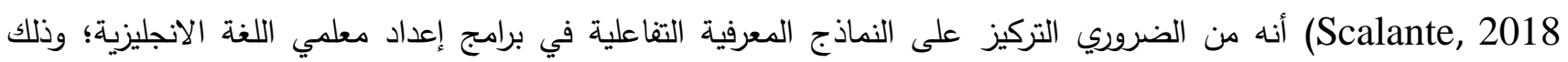

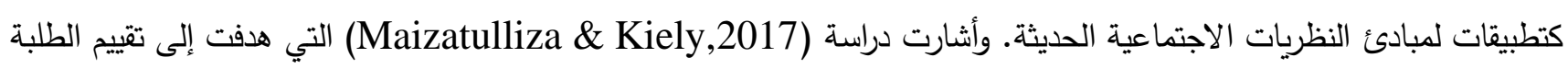

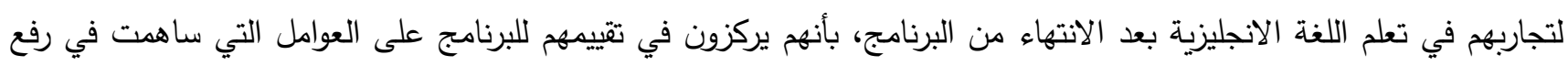

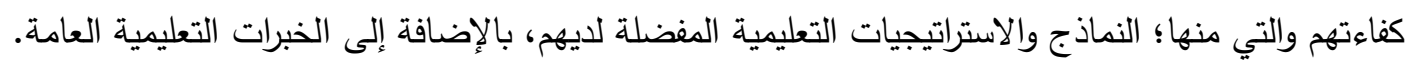

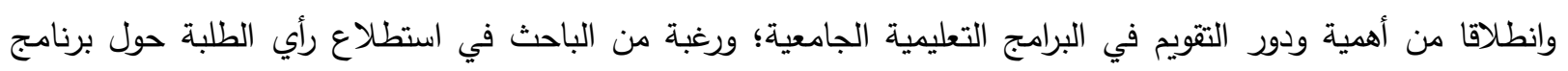

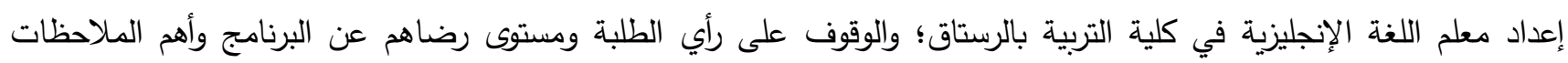
لايهم، فقد تلخصت الدراسة الحالية في الأسئلة البحثية الآتية:

ما نسبة الرضا العامة لطلبة اللغة الإنجليزية عن برنامج إعداد معلم اللغة الإنجليزية؟

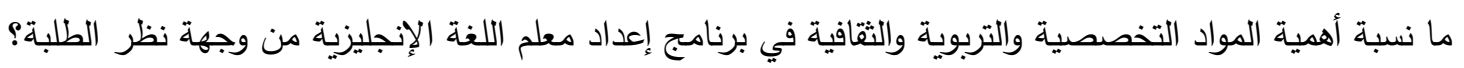

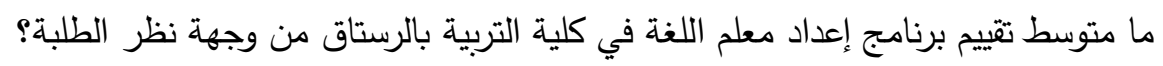

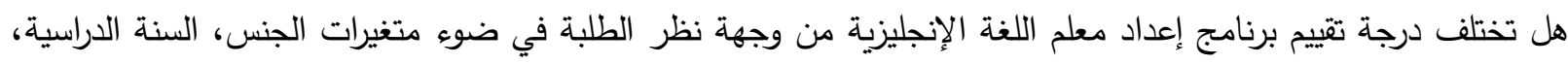




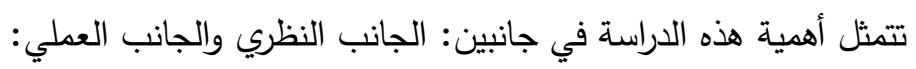

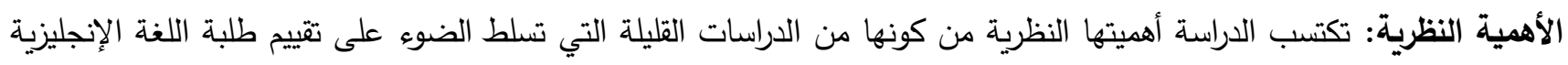

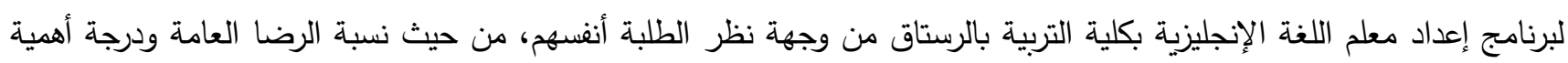

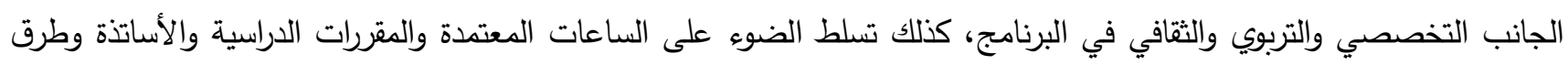
التدريس والأنشطة والبحوث واللوائح التتظيمية والإدارية.

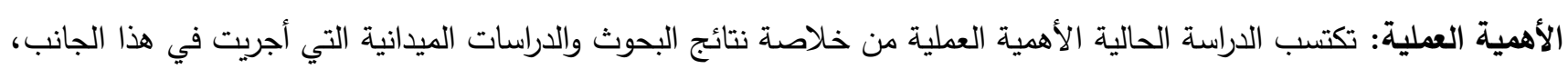

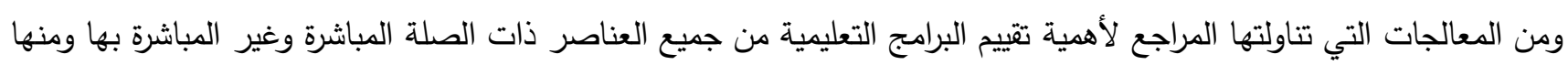

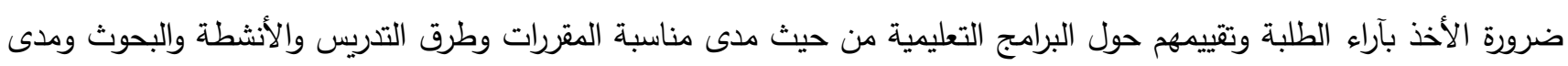
توافق نسبة الجانب النظري والجانب التطبيقي.

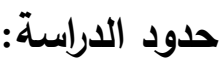

تتحدد هذه الدراسة بالدود الآتية:

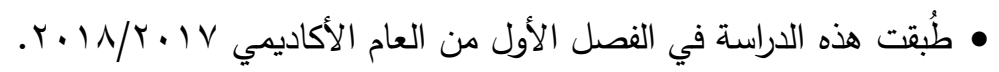

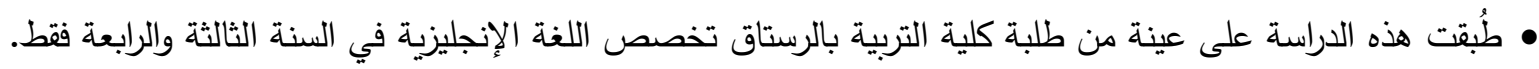

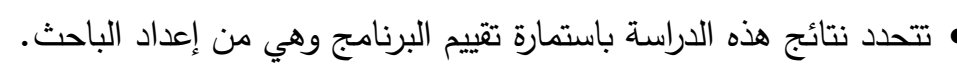

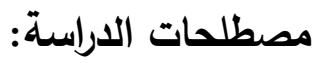

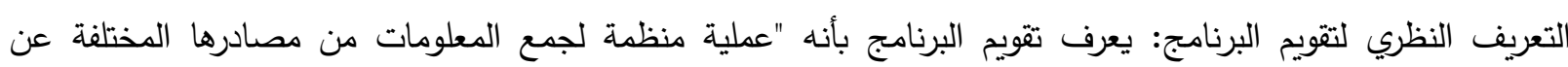

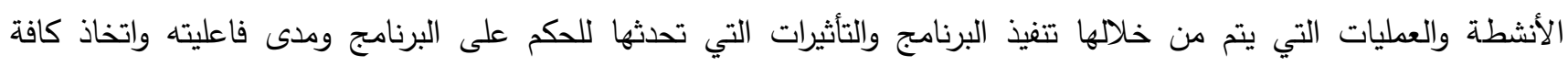

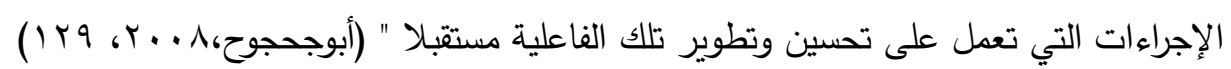

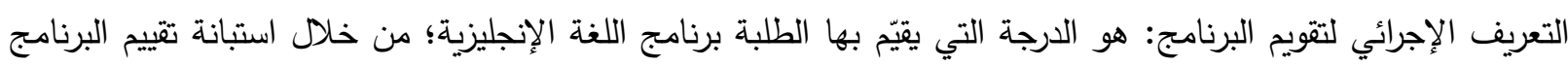
المستخدم في هذه الدراسة.

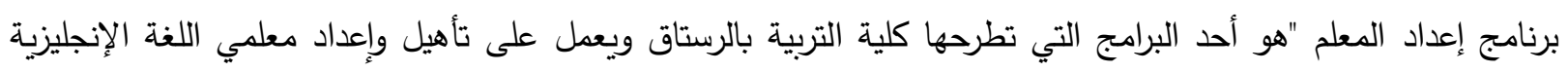

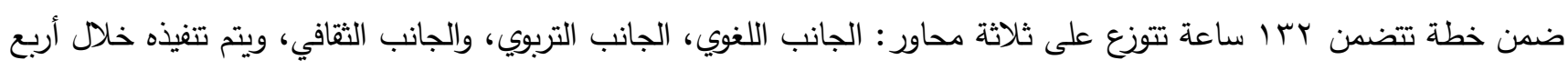
سنوات بالإضافة إلى السنة التأسيسية ".

\section{منهجية الدراسة:}

اعتمدت الدراسة الحالية على الدنهج الوصفي التحليلي كمنهج في عملية جمع البيانات وتحليلها. مجتمع الدراسة:

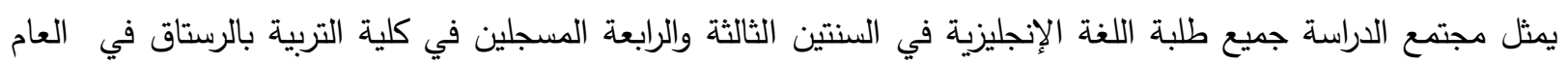

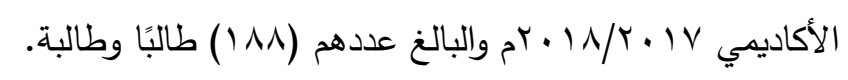

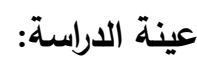

تكونت عينة عشوائية من (rو) طالبًا وطالبة من طلاب السنتين الثالثة والرابعة تخصص اللغة الإنجليزية من كلية التربية

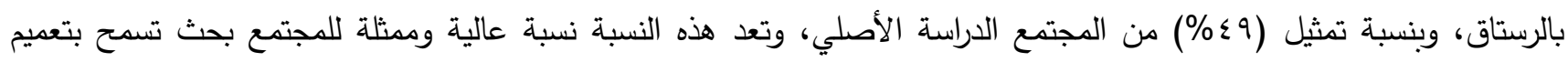
نتائج الدراسة. والجدول التالي يوضح نسب توزيع العينة في ضوء متغيرات الجنس والسنة الدراسية والتخصص: 
الجدول رقم ( ) : يوضح توزيع أفراد عينة الاراسة

\begin{tabular}{|c|c|c|c|}
\hline المجموع الكلي & العدد الع & \multicolumn{2}{|c|}{ الجنس/التخصص } \\
\hline \multirow[t]{2}{*}{94} & 09 & ل كر & \multirow[b]{2}{*}{ الجنس } \\
\hline & r & أنثى & \\
\hline \multirow[t]{2}{*}{$9 r$} & 0 . & الثالثة & \multirow[t]{2}{*}{ السنة الدراسية } \\
\hline & $\varepsilon r$ & الرابعة & \\
\hline $9 r$ & ar & \multicolumn{2}{|c|}{ المجموع } \\
\hline
\end{tabular}

أداة الدراسة:

استخدمت الدراسة الحالية أداة واحدة من إعداد الباحث هي استبانة تقييم برنامج إعداد المعلم، حيث تم بناء الاستبانة بعد

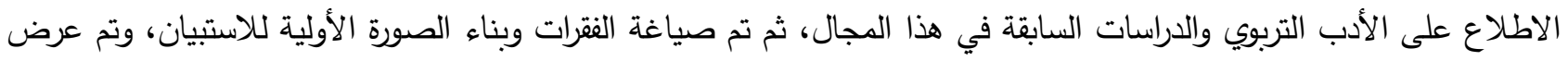
الاستبيان على المختصين التربويين في كلية التربية بالرستاق لمعرفة رأيهم في مدى مناسبة العبارات لما أعدت لقياساه، وتم الأخذ

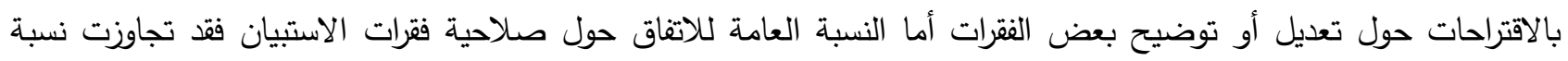

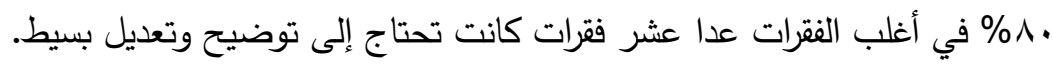

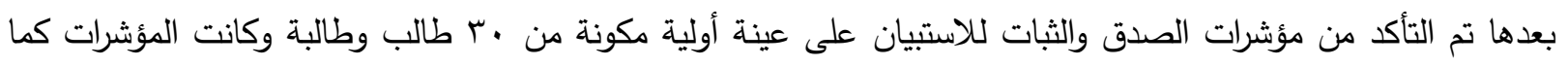

بالنسبة للثبات فقد تم اعتماد معامل ألفا لكرونباخ في حساب درجة الثبات للاستبيان وكانت مستوى الثبات للاستبيان بشكل عام (1)=0.95) وهي نسبة مقبولة جدا لمعاملات الثبات وتدل على تمتع المقياس بدرجة من الثبات تجعله صالحًا للاستخدام لأغراض الدراسة، ويوضح الجدول رقم (Y) قيم معاملات الثبات على محاور الاستبيان:

\begin{tabular}{|c|c|}
\hline قيمة معامل الثبات & المحور \\
\hline$\alpha=0.85$ & المحور الأول (المقررات والساعات) \\
\hline$\alpha=0.89$ & المحور الثاني (الأساتذة وطرق التدريس) \\
\hline$\alpha=0.85$ & المحور الثالث (الأنثطة والبحوث) \\
\hline$\alpha=0.85$ & المحور الرابع (الخدمات الإدارية) \\
\hline$\alpha=0.95$ & المقياس ككل \\
\hline
\end{tabular}

أما عن الصدق فقد تم حساب الصدق العاملي للاستبيان على التطبيق النهائي للدراسة وقد أفرزت نتائج التحليل أربعة عوامل هي: العامل الأول كان المقررات والساعات ويفسر ما نسبته (؟ء\%) من عمليات التقويم للبرنامج، والعامل الثاني كان الأساتذة وطرق التدريس ويفسر ما نسبته (rr\%) من عمليات التقويم للبرنامج، والعامل الثالث كان الأنشطة والبحوث ويفسر ما نسبته

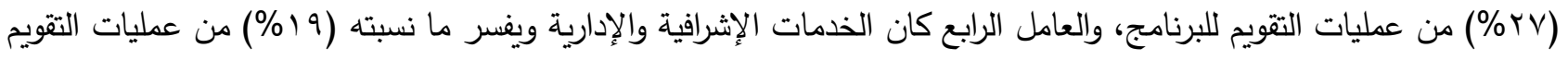
للبرنامج. والجدول رقم (r) يوضح تشبعات الفقرات على العوامل الأربعة للمقياس: 
الجدول رقم (ץ): يوضح تثبعات الفقرات على العوامل الأربعة على المقياس

\begin{tabular}{|c|c|c|c|c|c|}
\hline & & & & العبارة & لرقم \\
\hline $\mathbf{F 4}$ & $\mathbf{F 3}$ & $\mathbf{F 2}$ & F1 & & \\
\hline & & & & الأول: المقررات والساعات (F1) & لمحور \\
\hline & & & $\mathbf{0 . 6 4}$ & أهداف البرنامج واضحة ومحددة. & 1 \\
\hline & & & 0.60 & خطة توزيع البرنامج على السنوات الدراسية متوازنة. & r \\
\hline & & & 0.60 & خطة توزيع البرنامج على السنوات الدراسية مرنة. & $r$ \\
\hline & & & 0.60 & المقررات المطروحة في البرنامج متنوعة وشاملة. & ؛ \\
\hline & & & 0.59 & المقررات المطروحة في البرنامج متدرجة من حيث المستوى والصعوبة. & 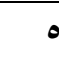 \\
\hline & & & $\mathbf{0 . 5 8}$ & أهداف المقرات واضحة ومحددة. & 9 \\
\hline & & & 0.58 & أهداف المقررات مناسبة وملائمة للطالب. & $v$ \\
\hline & & & 0.57 & أهداف المقرات متدرجة من حيث المستوى. & $\Lambda$ \\
\hline & & & $\mathbf{0 . 5 3}$ & المقررات المطرحة في البرنامج تكافئ المقرات في الجامعات الأخرى. & 9 \\
\hline & & & 0.51 & عدد الساعات المحتسبة للمقررات مناسبة. & 1. \\
\hline & & & 0.50 & تتنوع المقررات من حيث التخصص ما بين القواعد والأدب ..... & 11 \\
\hline & & & $\mathbf{0 . 4 9}$ & توازن المقرات بين الجانب التطبيقي والجانب النظري. & ir \\
\hline & & & 0.47 & أوقات طرح المقرات في الجداول الدراسية مناسبة. & ir \\
\hline & & & 0.46 & تتصف المقررات بالحداثة في المعلومات التي تقدمها. & $1 \varepsilon$ \\
\hline & & & 0.46 & هناك تكامل بين المقررات في المهارات التي تنميها للى الطالب. & 10 \\
\hline & & & 0.46 & نسبة الجانب التطبيقي في المقررات ملاثم. & 19 \\
\hline & & & $\mathbf{0 . 4 5}$ & المراجع والكتب المقترحة لكل مقرر ملائمة. & iv \\
\hline & & & $\mathbf{0 . 4 0}$ & المراجع والكتب المقترحة لكل مقرر متاحة. & 11 \\
\hline & & & $\mathbf{0 . 3 8}$ & المراجع والكتب المقترحة لكل مقر حديثة. & 19 \\
\hline & & & $\mathbf{0 . 3 3}$ & نسبة المقرات التخصصية الاجبارية ملائمة. & r. \\
\hline & & & $\mathbf{0 . 3 3}$ & نسبة المقرات التخصصية الاختيارية ملائمة. & $r$ \\
\hline & & & 0.32 & نسبة المقررات التربوية ملائمة. & rr \\
\hline & & & $\mathbf{0 . 3 0}$ & نسبة المقررات الثقافية ملائمة. & rr \\
\hline & & & & الثاني: الأساتذة وطرق التلديس (F2) & لمحو - la \\
\hline & & $\mathbf{0 . 6 0}$ & & عدد الأساتذة بالنسبة لعدد المقررات مناسب. & 1 \\
\hline & & 0.55 & & عدد الطلبة بالنسبة لكل مجموعة مناسب. & r \\
\hline & & $\mathbf{0 . 5 3}$ & & كفاءة الأساتذة بالنسبة للمقرات مناسبة. & $r$ \\
\hline & & $\mathbf{0 . 5 0}$ & & هناك تنوع في جنسيات مدرسي المقررات وبالتالي تنوع في الخبرات. & $\varepsilon$ \\
\hline & & 0.47 & & المهارات التي يركز عليها الأساتذة مختلفة. & 。 \\
\hline & & $\mathbf{0 . 4 5}$ & & يستخدم الأساتذة طرق تدريس متنوعة. & 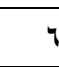 \\
\hline & & 0.44 & & طرق التدريس التي يستخذمها الأساتذة ملائمة. & 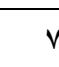 \\
\hline & & 0.44 & & طرق التدريس التي يستخدمها الأساتذة حديثة. & $\wedge$ \\
\hline & & 0.44 & & طرق التدريس التي يستخدما الأساتذة مبتكرة. & 9 \\
\hline & & 0.42 & & يستخدم الأستاذة تقنيات وتكنولوجيا حديثة في التريس. & 1. \\
\hline & & $\mathbf{0 . 4 1}$ & & يستخدم الأساتذة مهارات تفكير مختلفة أثناء التدريس. & 11 \\
\hline & & 0.40 & & يستخدم الأساتذة طرق تدريس تعمل على تنمية الحوار والنقاش مع الطلبة. & ir \\
\hline & & $\mathbf{0 . 3 8}$ & & يستذذم الأساتذة طرق تدريس تعمل على تنمية مهارات النقد البناء. & ir \\
\hline & & 0.34 & & يستخدم الأساتذة طرق تدريس تعمل على تنمية مهارات التفكير الإبداعي. & $1 \&$ \\
\hline
\end{tabular}




\begin{tabular}{|c|c|c|c|c|}
\hline & & $\mathbf{0 . 3 3}$ & يركز الأساتذة على إيجابية الطالب وإشراكه النثط في عملية التعلم. & 10 \\
\hline & & $\mathbf{0 . 3 2}$ & يشجع الأساتذة على التعاون والتشارك بين الطلبة خلال عملية التعلم. & 19 \\
\hline & & $\mathbf{0 . 3 2}$ & يظهر الأساتذة مرونة وتعاون جيد في تعاملهم مع الطلبة. & iv \\
\hline & & $\mathbf{0 . 3 0}$ & طرق التدريس التي يستخذمها الأساتذة تراعي الفروق الفردية في المستويات بين & 11 \\
\hline & & $\mathbf{0 . 3 0}$ & يستذدم الأساتذة التعلم الإكتروني E-Learning في التدريس. & 19 \\
\hline & & $\mathbf{0 . 3 0}$ & يستخدم الأستاذة نظام البلاك برود Black Board في التواصل مع الطلبة. & $r$. \\
\hline \multicolumn{5}{|c|}{ المحور الثالث: الأنثطة والبحوث (F3) } \\
\hline & $\mathbf{0 . 5 3}$ & & الأنثطة والبحوث والمشاريع الطلابية لكل مقرر مناسبة. & 1 \\
\hline & 0.51 & & هناك توازن بين التكاليف المطلوبة لكل مقر وساعاته المتتدة. & r \\
\hline & $\mathbf{0 . 5 0}$ & & هناك تلاوم بين التكاليف المطلوبة وطبيعة المعلومات النظرية في المقرر. & $r$ \\
\hline & $\mathbf{0 . 4 9}$ & & الأنثطة والبحوث الطلابية تنمي المهارات التطبيقية للمقررات. & $\varepsilon$ \\
\hline & 0.49 & & حجم الجه المطلوب لتنفيذ الأنثطة والبحوث ملائم في الفصل الدراسي. & ○ \\
\hline & 0.48 & & الزمن المطلوب لتنفيذ الأنثطة والبحوث ملائم بالنسبة للفصل الداسسي. & 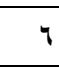 \\
\hline & 0.46 & & ينوع الأساتذة في طبيعة الأنثطة والبحوث والمشاريع المطلوبة لكل مقرد. & $\mathrm{v}$ \\
\hline & 0.44 & & يتيح الأساتذة للطلبة حرية اختيار موضوع البحث أو المشروع أو النشاط. & $\wedge$ \\
\hline & 0.43 & & يثجع الأساتذة الطلبة على ابتكار موضوع البحث والمشروع. & 9 \\
\hline & $\mathbf{0 . 4 1}$ & & البحوث والمشاريع الطلابية. & 1. \\
\hline & 0.40 & & الذذمات الإثرافية التي يقدمها الأساتذة على المشاريع الطلابية مناسبة. & 11 \\
\hline & $\mathbf{0 . 3 9}$ & & يثجع الأساتذة العمل التعاوني بين الطلاب في تنفيذ المشروعات والأنثطة. & ir \\
\hline & $\mathbf{0 . 3 6}$ & & الأنثطة والبحوث والمشاريع الطلابية تراعي الفروق التحصيلية بين الطلبة. & ir \\
\hline & $\mathbf{0 . 3 6}$ & & تركز الأنثطة والبحوث والمشاريع على تنمية مهارات مهنية لاى الطلبة. & $1 \leqslant$ \\
\hline & $\mathbf{0 . 3 6}$ & & تركز الأنشطة والبحوث والمشاريع على تنمية مهارات شخصية لاى الطلبة. & 10 \\
\hline & $\mathbf{0 . 3 4}$ & & تركز الأنثطة والبحوث والمشاريع تنمية مهارات عقلية معرفية لاى الطلبة. & 14 \\
\hline & $\mathbf{0 . 3 1}$ & & تركز الأنثطة والبحوث والمشاريع على تنمية مهارات لغوية لاى الطلبة. & iv \\
\hline & $\mathbf{0 . 3 1}$ & & الارجات المخصصة للأنثطة والبحوث والمشاريع الطلابية مناسبة. & 11 \\
\hline & $\mathbf{0 . 3 0}$ & & معايير قبول وتقييم الأنثطة والبحوث والمشاريع واضحة ومحددة. & 19 \\
\hline \multicolumn{5}{|c|}{ المحور الرابع: الذذمات الإشرافية والإدارية(F4) } \\
\hline 0.57 & & & السياسات الإدارية للبرنامج واضحة ومحددة في رؤية ورسالة وأهداف القسم. & 1 \\
\hline 0.55 & & & يدير القسم أساتذة مختصين وذي خبرات عالية. & $r$ \\
\hline 0.55 & & & بالطلبة. & $r$ \\
\hline 0.54 & & & تتعامل إدارة القسم وأساتنته بطريقة ديمقراطية وحوارية في التعامل مع الطلبة. & $\varepsilon$ \\
\hline $\mathbf{0 . 5 3}$ & & & يسود الود والتفاهم في التعامل بين أساتذة القسم والطلبة. & 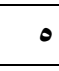 \\
\hline 0.49 & & & يسهل القسم الإجراءات الإدارية الخاصة بمعاملات الطلبة مع الأقسام الأخرى. & 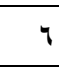 \\
\hline 0.49 & & & عدد الطلبة في مجموعات الإرشاد الأكاديمي مناسبة بالنسبة لعدد الأساتذة. & $\mathrm{v}$ \\
\hline $\mathbf{0 . 4 8}$ & & & الساعات المكتبية لكل أستاذ مقرر مناسب بالنسبة لعدد الطلبة لكل مجموعة. & $\wedge$ \\
\hline $\mathbf{0 . 4 3}$ & & & أوقات الساعات المكتبية وساعات الإرشاد الأكاديمي مناسبة لأوقات الطلبة. & 9 \\
\hline 0.41 & & & يستثر الطلبة جيدا الساعات المكتبية التي يحددها الأساتذة لكل مقرر. & 1. \\
\hline 0.38 & & & يقدم الأساتذة خدمات جيدة في الساعات الأكاديمية. & 11 \\
\hline 0.33 & & & يراعي الأساتذة الفروق الفردية في التحصيل خلال لقاهم بالطلبة في الساعات & Ir \\
\hline
\end{tabular}




\begin{tabular}{|c|c|c|c|c|c|}
\hline & & & & المكتبية والساعات الإرشادية. & \\
\hline 0.32 & & & & خلال الساعات الأساتذة على تقديم الإيضاحات اللازمة والثشرح الكافي لما يطلبه الطلبة & Ir \\
\hline $\mathbf{0 . 3 0}$ & & & & 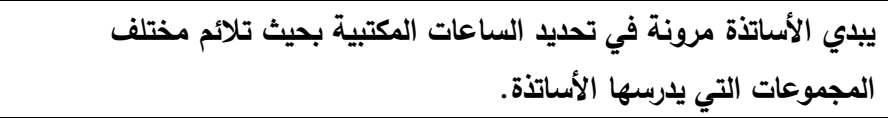 & $1 \leq$ \\
\hline 0.30 & & & & يبلي الأساتذة مرونة في مقابلة الطلبة خارج نطاق الساعات المكتبية إذا دعت & 10 \\
\hline 0.30 & & & & 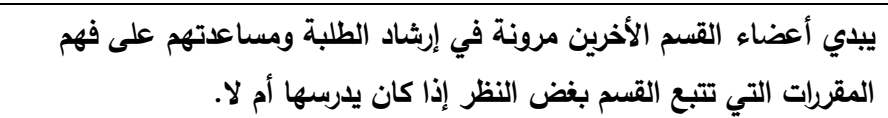 & 17 \\
\hline 0.19 & 0.27 & 0.32 & 0.44 & باين المفسر على العامل & نسبة \\
\hline
\end{tabular}

الأساليب الإحصائية:

استخدمت الدراسة الحالية عدداً من الأساليب الإحصائية التي تحقق الإجابة عن تساؤلات الدراسة ومنها: المتوسطات

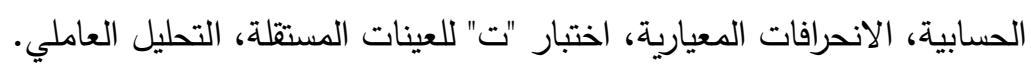

نتائج الاراسة ومناقشتها:

في هذا الجزء من الدراسة سوف يتم عرض ومناقشة نتيجة كل سؤال على حدة.

أولاً: نتائج السؤال الأول هن

بالنسبة للسؤال الأول في للدراسة الذي نص على " ما نسبة الرضا العامة لطلبة اللغة الإنجليزية عن برنامج إعداد معلم اللغة

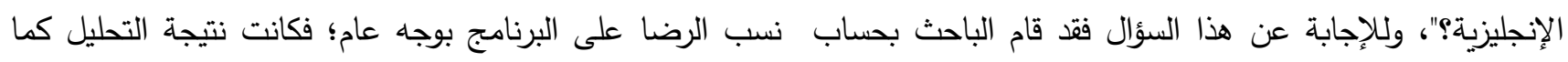
يوضحها الجدول الآتي:

جدول رقم (؛): يوضح نسب الرضا العامة على البرنامج

\begin{tabular}{|c|c|c|c|c|}
\hline نسبة الدلالة & قيمة & النسبة & | العدد & نسبة الرضا \\
\hline$\alpha=0.50$ & $r v, r$ & $\%$. & $\cdot$ & $\%$. \\
\hline$\alpha=0.05$ & $r \cdot, \cdot \Lambda$ & $\% \backslash \bullet, r$ & $1 \leq$ & $\%$ ro \\
\hline$\alpha=0.05$ & $I r, O V$ & $\%$ \% , द & rA & $\% 0$. \\
\hline$\alpha=0.05$ & $r \cdot, q$ & $\% \leqslant \leqslant, 4$ & $\leqslant 1$ & $\%$ \% \\
\hline$\alpha=0.05$ & $\mid \vee, \wedge \wedge$ & $\% ৭, \wedge$ & 9 & $\% 1 \ldots$ \\
\hline & & $\% 1 \ldots$ & $a r$ & المجموع \\
\hline
\end{tabular}

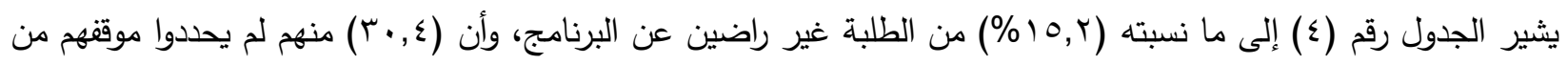

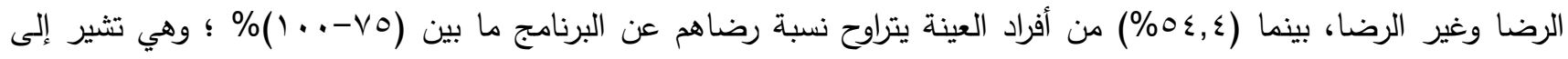

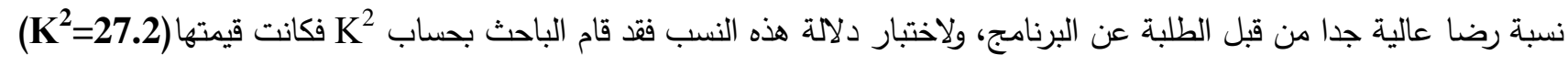
عند درجات حرية (DF=4) وهي قيمة دالة عن مستوى (a=0.05) وهذا يعني أن الفروق بين نسبة الرضا المشاهدة والنسبة المتوقعة كانت ذات فروق حقيقية. 
ويرى الباحث أن هذه النسبة طبيعية جدا وتعبر بشكل واقعي عن الرضا لدى الطلبة عن البرنامج، وأن هذه النتيجة بالرغم من

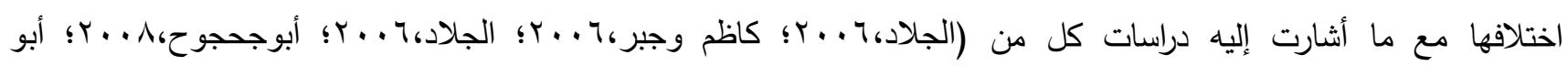

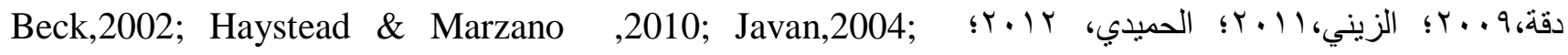
(Montgomery,2000; $ح و ل$ مستوى الرضا العام لاي الطلبة عن البرامج الأكاديمية. ثانياً: نتائج السؤال الثاني بالنسبة للسؤال الثاني في الدراسة الذي نص على " ما نسبة أهمية المواد التخصصية والتربوية والثقافية في برنامج إعداد معلم اللغة الإنجليزية من وجهة نظر الطلبة؟"، ولإجابة عن هذا السؤال فقد قام الباحث بحساب نسب نسب أهمية المواد التخصصية والمواد

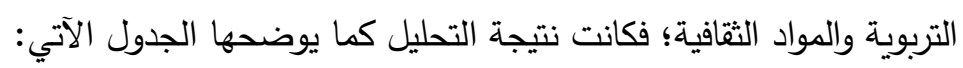

جدول رقم (ه): يوضح نسب الأهمية عن المقررات التخصصية والتربوية وإلثقافية

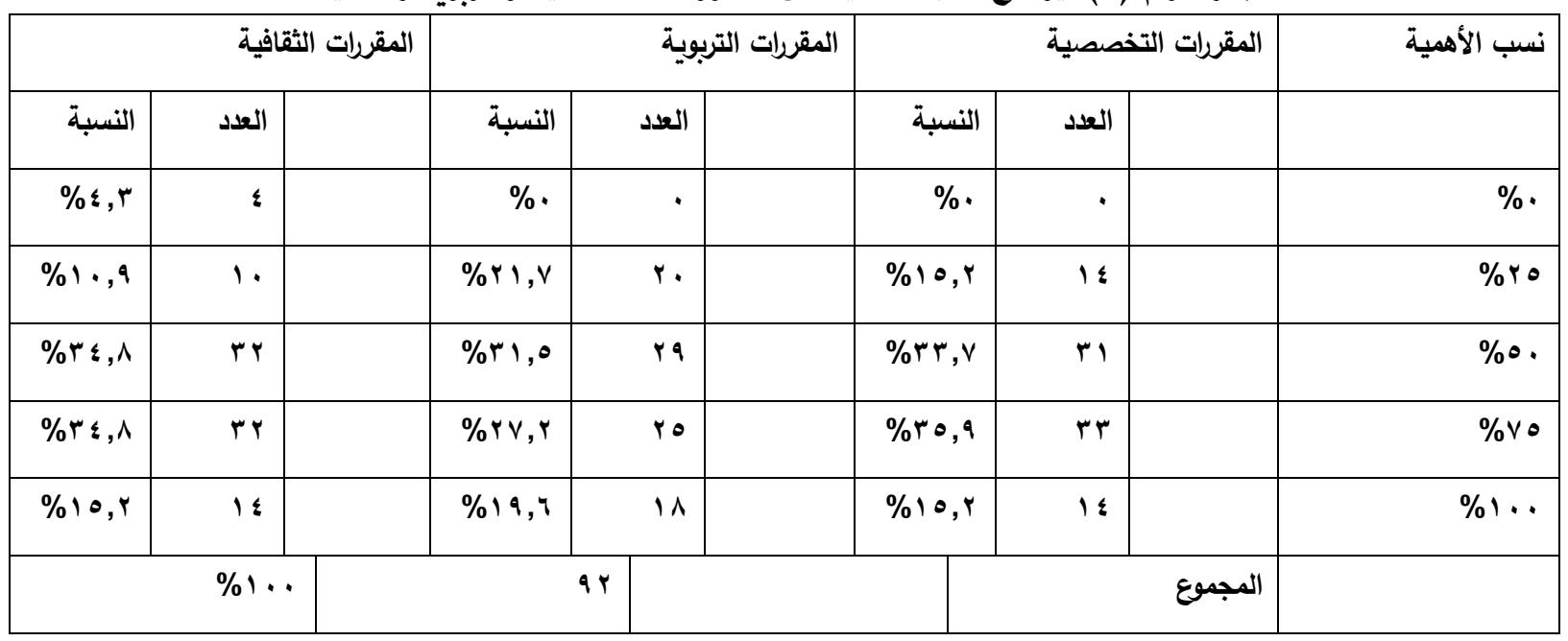

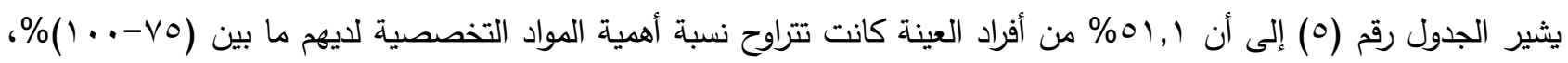

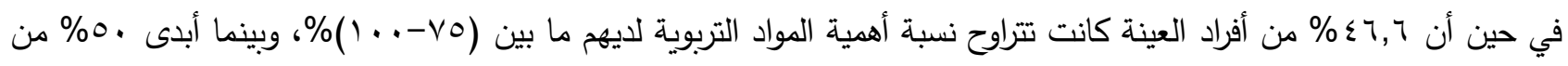

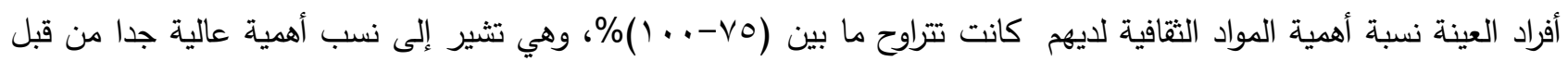

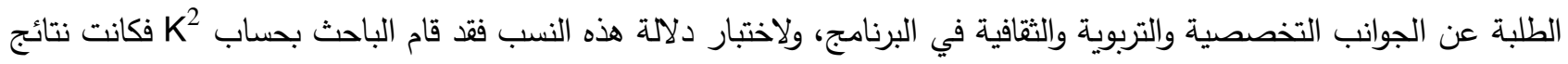
اختبار Kما يوضح عها الجدول الآتي:

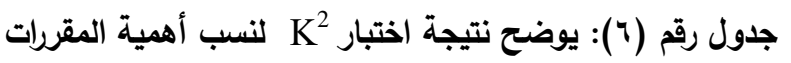

\begin{tabular}{|c|c|c|c|}
\hline نسبة الدلالة & DF & قيمة K2 & المجال \\
\hline$\alpha=0.05$ & $\varepsilon$ & $1 \leqslant, r$ & المساقات التخصيصية \\
\hline$\alpha=0.05$ & $\varepsilon$ & $r r, \xi$ & المساقات التربوية \\
\hline$\alpha=0.05$ & $\varepsilon$ & $r q, r$ & المساقات التربوية \\
\hline
\end{tabular}

يثير الجدول رقم (؟) إلى أن الفروق بين النسب المشاهدة والمتوقعة لأهمية المساقات التخصيصية والتربوية والثقافية كانت

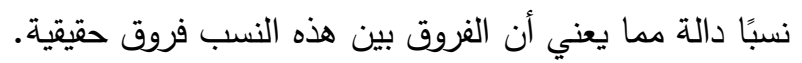

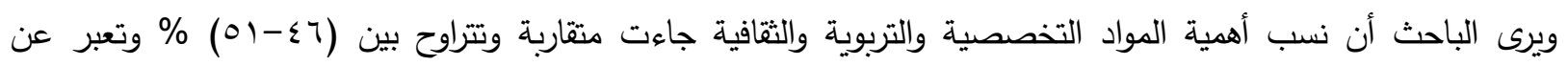

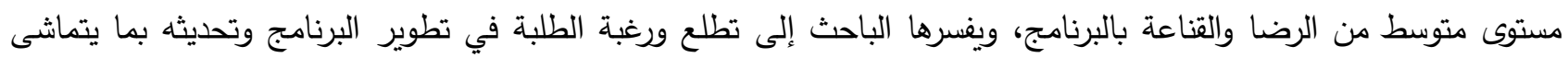

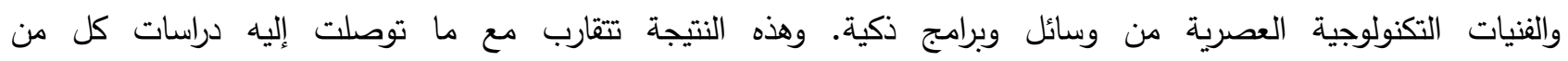

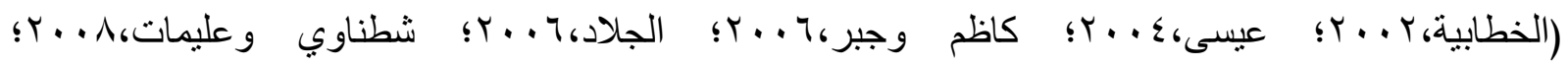




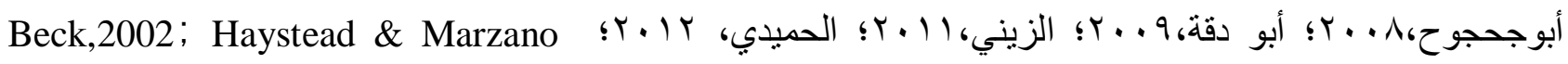
(,2010; Javan,2004; Montgomery,2000;

ثالثاً: نتائج السؤال الثالث

بالنسبة للسؤال الثالث في للدراسة الذي نص على " ما متوسط تقييم برنامج إعداد معلم اللغة في كلية التربية بالرستاق من وجهة

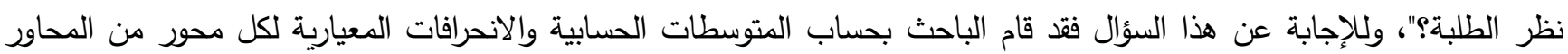
على القائمة، وكانت النتائج كما يوضحها الجدول (V) والثكل (l) (l) الآتي: جدول رقم (V): يوضح المتوسطات على المحاور والدرجة الكلية

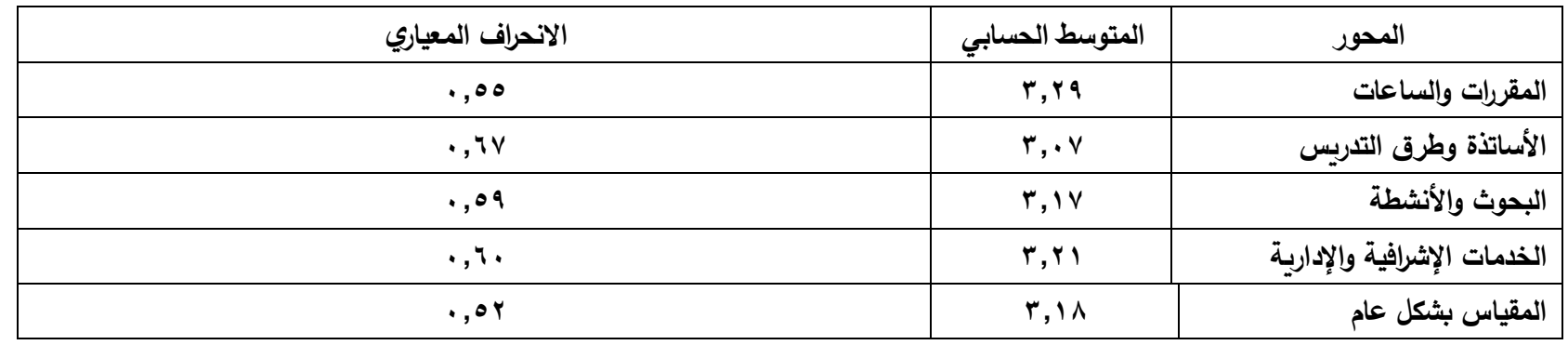

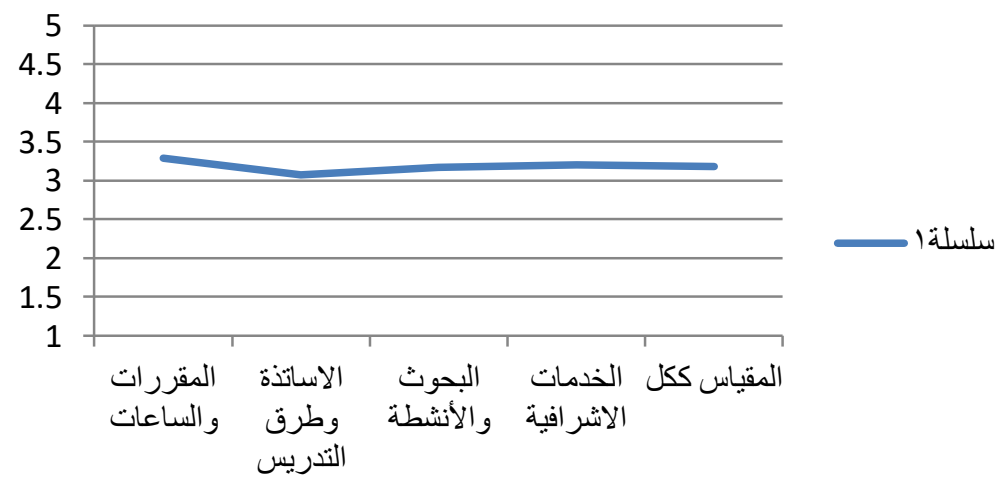

شكل رقم ( ) : يوضح المتوسطات على المحاور واللارجة الكلية

يلاحظ من الجدول (V) والشكل رقم (1) أن درجة تقييم البرنامج بوجه عام من وجهة نظر الطلبة كانت متوسطة حيث بلغ

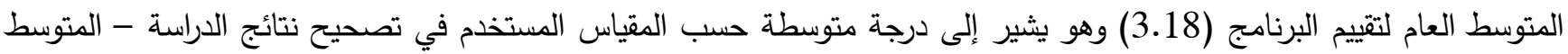

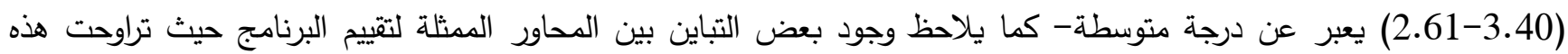

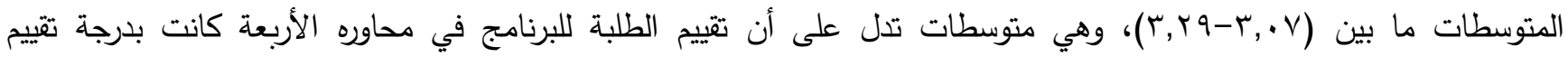
متوسطة، حسب المقياس المستخدم في تصحيح نتائج الدراسة - المتوسط (3.40-2.61) يعبر عن درجة متوسطة، حيث جاء محور

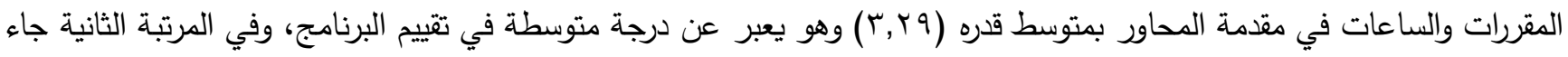

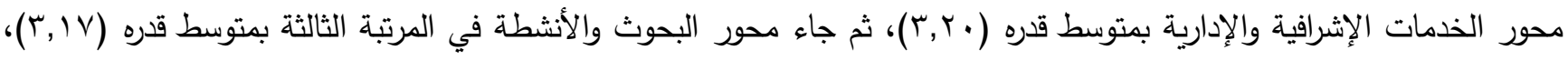
وفي المرتبة الرابعة جاء محور الأساتذة وطرق التدريس بمتوسط قدره (V.,r). وجميع المتوسطات على المحاور الأربعة تدل على

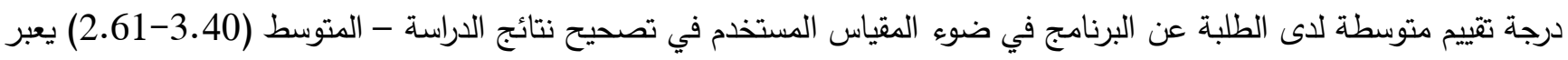
عن درجة متوسطة. ولاختبار دلالة المتوسطات الحسابية على كل عامل من العوامل السابقة فقد قام الباحث باستخدام اختبار "ت" للعينة الواحدة "one sample T-test" للعينة الواحدة كما يوضحها الجدول رقم (^): 
جدول رقم (^): يوضح نتائج اختبار "ت" للعينة الواحدة للمحاور الستة

\begin{tabular}{|c|c|c|c|c|}
\hline الالالة & DF & قيمة "ت" & المتوسط & المحور \\
\hline$\alpha=0.05$ & 91 & $0, \cdot r$ & $r, r q$ & المقررات والساعات \\
\hline$\alpha=0.05$ & 91 & $1, .0$ & $r, r_{1}$ & الخدمات الإدارية والإشرافية \\
\hline$\alpha=0.05$ & 91 & $r, \wedge r$ & r,IV & البحوث والأنثطة \\
\hline$\alpha=0.48$ & 91 & r,r & $r, \cdot v$ & الأساتذة وطرق التدريس \\
\hline$\alpha=0.05$ & 91 & $r, r$. & $r, 1 \Lambda$ & المقياس بثكل عام \\
\hline
\end{tabular}

وتثير نتائج اختبار "ت" للعينة الواحدة في الجدول رقم (^)؛ إلى أن هناك فروقًا دالة إحصائياً عند مستوى (م) (م) بين المتوسطات الحسابية المحسوبة لمعظم المحاور والمتوسط الفرضي، وهذا يعني أن الفروقات الظاهرة بين المتوسطات الحسابية لدحاور والمتوسط المفترض للمقياس وهو الدرجة (r) هي فروق حقيقية مؤثرة. عدا محور الأساتذة وطرق التدريس التي لا توجد فروق بين لئن المتوسط الواقعي والمتوسط الفرضي. وبصورة عامة فإن هذا يدل على أن مستوى تقييم الطلبة للبرنامج جاء بدرجة متوسطة؛ وأنه يوجد

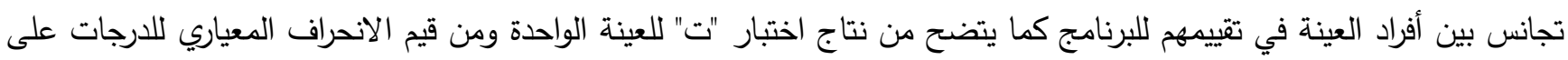
جميع المحاور · one sample T-test أما من حيث تأثير العبارات لكل محور فقد استخدم الباحث المتوسطات الحسابية، ثم استخدم اختبار لاختبار دلالة هذه المتوسطات، وكانت نتائج الاختبار على النحو الآتي: بالنسبة للمحور الأول: الحاجات الأكاديمية دلاته جدول رقم (9): يوضح فقرات المحور الأول من حيث قوة تأثيرها، كذلك يوضح نتائج اختبار "ت" لالالة هذه المتوسطات

\begin{tabular}{|c|c|c|c|c|c|}
\hline 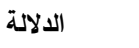 & DF & 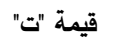 & المتوسط & 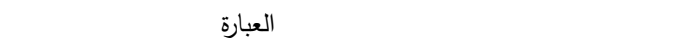 & 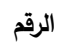 \\
\hline$\alpha=0.05$ & 91 & $\mathrm{v}, \ldots$ & $r, v i$ & أهداف البرنامج واضحة ومحددة. & 1 \\
\hline$\alpha=0.05$ & 91 & $r, 1$. & $r, r r$ & خطة توزيع البرنامج على السنوات الدراسية متوازنة. & $r$ \\
\hline$\alpha=0.05$ & 91 & $1,9$. & r, r & خطة توزيع البرنامج على السنوات الدراسية مرنة. & $r$ \\
\hline$\alpha=0.05$ & 91 & r,q. & $r, r \leq$ & المقررات المطروحة في البرنامج متنوعة وشاملة. & \{ \\
\hline$\alpha=0.05$ & 91 & $\varepsilon, r q$ & $r, \varepsilon \vee$ & المقررات المطروحة في البرنامج متدرجة من حيث المستوى والصعوبة. & • \\
\hline$\alpha=0.05$ & 91 & $r, r^{\prime}$ & $r, r v$ & أهداف المقررات واضحة ومحددة. & 9 \\
\hline$\alpha=0.05$ & 91 & $1,9 \vee$ & r,re & أهداف المقررات مناسبة وملائمة للطالب. & $v$ \\
\hline$\alpha=0.05$ & 91 & $r, .4$ & $r, r r$ & أهداف المقررات متدرجة من حيث المستوى. & $\wedge$ \\
\hline$\alpha=0.05$ & 91 & $1, .7$ & $r, r \cdot$ & المقررات المطرحة في البرنامج تكافئ المقررات في الجامعات الأخرى. & 9 \\
\hline$\alpha=0.05$ & 91 & rit & $r, r \leq$ & عدد الساعات المحتسبة للمقررات مناسبة. & 1. \\
\hline$\alpha=0.43$ & 91 & $\varepsilon, 0 \wedge$ & r,or & تتنوع المقررات من حيث التخصص ما بين القواعد والأدب ..... & 11 \\
\hline$\alpha=0.05$ & 91 & 1,90 & $r, r \varepsilon$ & توازن المقررات بين الجانب التطبيقي والجانب النظري. & ir \\
\hline$\alpha=0.11$ & 91 & $\cdot, 10-$ & r,q^ & أوقات طرح المقررات في الجداول الدراسية مناسبة. & ir \\
\hline$\alpha=0.05$ & 91 & $r, r \cdot$ & $r, r v$ & تتصف المقررات بالحداثة في المعلومات التي تقدمها. & $1 \leqslant$ \\
\hline$\alpha=0.05$ & 91 & $1, r_{1}$ & $r, 1 \leqslant$ & هناك تكامل بين المقررات في المهارات التي تنميها لاى الطالب. & 10 \\
\hline$\alpha=0.42$ & 91 & $\cdot, \wedge \cdot-$ & $r, q$. & نسبة الجانب التطبيقي في المقررات ملائم. & 17 \\
\hline$\alpha=0.16$ & 91 & $1, \leqslant 1$ & $r, I V$ & المراجع والكتب المقترحة لكل مقرر ملائمة. & iv \\
\hline$\alpha=0.22$ & 91 & $1, r \mathrm{r}$ & $r, 10$ & المراجع والكتب المقترحة لكل مقرر متاحة. & 11 \\
\hline$\alpha=0.86$ & 91 & $\cdot, \wedge$ & $r, 11$ & المراجع والكتب المقترحة لكل مقرر حديثة. & 19 \\
\hline$\alpha=0.05$ & 91 & $r, 79$ & $r, \leqslant r$ & نسبة المقررات التخصصية الإجبارية ملائمة. & r. \\
\hline$\alpha=0.05$ & 91 & $\varepsilon, r$. & $r, \leqslant 0$ & نسبة المقررات التخصصية الاختيارية ملائمة. & r \\
\hline$\alpha=0.05$ & 91 & $\leq, \infty$ & $r, 0$. & نسبة المقررات التربوية ملائمة. & rr \\
\hline$\alpha=0.05$ & 91 & $r, 10$ & $r, \varepsilon$. & نسبة المقررات الثقافية ملائمة. & rr \\
\hline
\end{tabular}




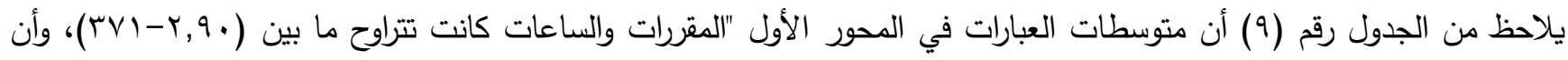

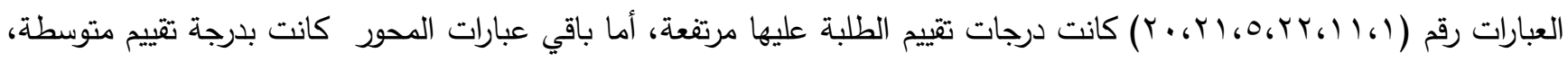

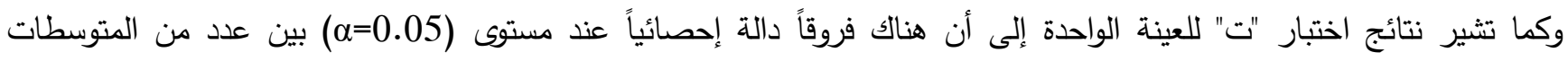
الحسابية المحسوبة للفقرات على هذا المحور والمتوسط الفرضي، وهذا يعني أن الفروقات الظاهرة بين المتوسطات الحسابية لهذه الفقرات والمتوسط المفترض (r) هي فروق حقيقية مؤثرة. بالنسبة للمحور الثاني: الأساتذة وطرق التدريس: جدول رقم (• (1): يوضح فقرات المحور الثاني من حيث قوة تأثيرها، كذلك يوضح نتائج اختبار "ت" لدلالة هذه المتوسطات

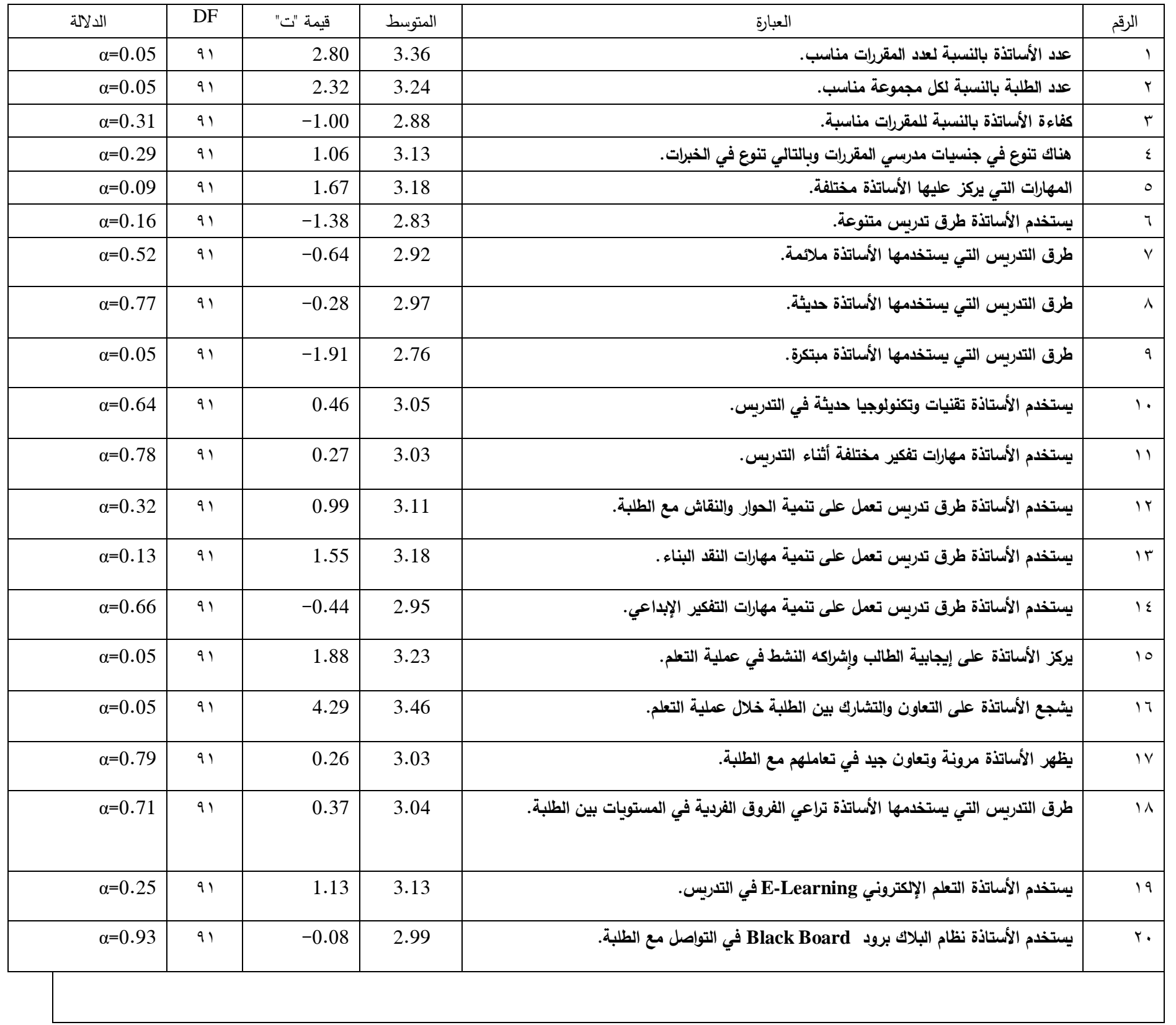

ويلاحظ من الجدول رقم (·) (1) أن متوسطات العبارات في المحور الثاني "الأساتذة وطرق التدريس" كانت تتراوح ما بين

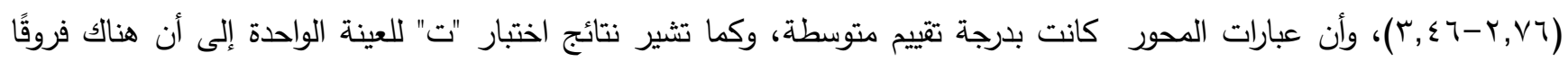

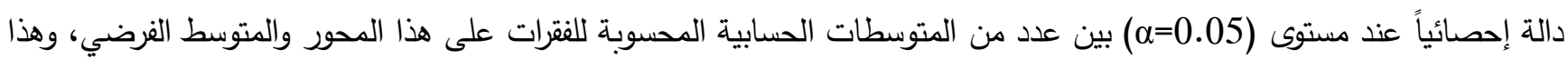
يعني أن الفروقات الظاهرة بين هذه المتوسطات الحسابية للفقرات والمتوسط المفترض (r) هي فروق حقيقية مؤثرة. 
بالنسبة للمحور الثالث: البحوث والأنثطة:

جدول رقم (11): يوضح فقرات المحور الثالث من حيث قوة تأثيرها، كذلك يوضح نتائج اختبار "ت" لالالة هذه المتوسطات

\begin{tabular}{|c|c|c|c|c|c|}
\hline 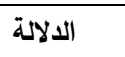 & DF & قيمة "ت" & المتوسط & 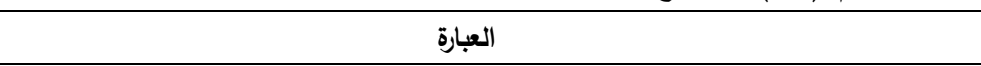 & 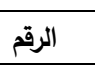 \\
\hline$\alpha=0.05$ & 91 & $r, T V$ & r r & الأنثطة والبحوث والمشاريع الطلابية لكل مقرر مناسبة. & 1 \\
\hline$\alpha=0.05$ & 91 & $1, \vee \wedge$ & r, r & هناك توازن بين التكاليف المطلوبة لكل مقرر وساعاته المعتمدة. & r \\
\hline$\alpha=0.20$ & 91 & $1, r V$ & $r, 1 \varepsilon$ & هناك تلاءم بين التكاليف المطلوبة وطبيعة المعلومات النظرية في المقرد. & r \\
\hline$\alpha=0.57$ & 91 &., 07 & $r, \cdot v$ & الأنثطة والبحوث الطلابية تنمي المهارات التطبيقية للمقرات. & $\varepsilon$ \\
\hline$\alpha=0.99$ & 91 & $\cdot, \cdots$ & $r, \ldots$ & حجم الجها المطلوب لتنفيذ الأنثطة والبحوث ملائم في الفصل الدراسي. & $\circ$ \\
\hline$\alpha=0.79$ & 91 & $\cdot, r_{0}$ & $r, \cdot r$ & الزمن المطلوب لتنفيذ الأنثطة والبحوث ملائم بالنسبة للفصل الدراسي. & 7 \\
\hline$\alpha=0.84$ & 91 & $\cdot, r \cdot$ & $r, \cdot r$ & ينوع الأساتذة في طبيعة الأنثطة والبحوث والمشاريع المطلوبة لكل مقرر. & $\mathrm{V}$ \\
\hline$\alpha=0.05$ & 91 & $r, r \leq$ & r, ro & يتيح الأساتذة للطلبة حرية اختيار موضوع البحث أو المشروع أو النشاط. & $\wedge$ \\
\hline$\alpha=0.43$ & 91 & $\cdot, \vee \wedge$ & $r, 1$. & يثجع الأساتذة الطلبة على ابتكار موضوع البحث والمشروع. & 9 \\
\hline$\alpha=0.05$ & 91 & $r, 1 \wedge$ & $r, r \varepsilon$ & يقدم الأساتذة المساعدة للطلبة للتظب على التحديات التي يواجهونها في تنفيذ البحوث والمشاريع & 1. \\
\hline$\alpha=0.05$ & 91 & $r, \varepsilon \wedge$ & $r, r q$ & الخدمات الإثرافية التي يقدمها الأساتذة على المثاريع الطلابية مناسبة. & 11 \\
\hline$\alpha=0.05$ & 91 & $r, T V$ & r, ג & يثجع الأساتذة العمل التعاوني بين الطلاب في تنفيذ المشروعات والأنثطة. & it \\
\hline$\alpha=0.63$ & 91 & $\cdot, \sum \mathrm{V}$ & $r, .0$ & الأنثطة والبحوث والمشاريع الطلابية تراعي الفروق التحصيلية بين الطلبة. & ir \\
\hline$\alpha=0.99$ & 91 & $\cdot, \cdots$ & $r, \ldots$ & تركز الأنثطة والبحوث والمشاريع على تنمية مهارات مهنية لاى الطلبة. & $1 \leq$ \\
\hline$\alpha=0.99$ & 91 & $\cdot, \cdots$ & $r, \ldots$ & تركز الأنثطة والبحوث والمشاريع على تنمية مهارات شخصية لاى الطلبة. & 10 \\
\hline$\alpha=0.05$ & 91 & $r, 10$ & r, ra & تركز الأنثطة والبحوث والمشاريع تنمية مهارات عقلية معرفية لاى الطلبة. & 17 \\
\hline$\alpha=0.05$ & 91 & r, ^० & $r, r \leq$ & تركز الأنثطة والبحوث والمشاريع على تنمية مهارات لغوية لاى الطلبة. & iv \\
\hline$\alpha=0.52$ & 91 &., $7 \leqslant$ & $r, \cdot \Lambda$ & الارجات المخصصة للأنثطة والبحوث والمشاريع الطلابية مناسبة. & 11 \\
\hline$\alpha=0.05$ & 91 & $r, \wedge 0$ & $r, \leqslant 9$ & معايير قبول وتقييم الأنثطة والبحوث والمشاريع واضحة ومحددة. & 19 \\
\hline
\end{tabular}

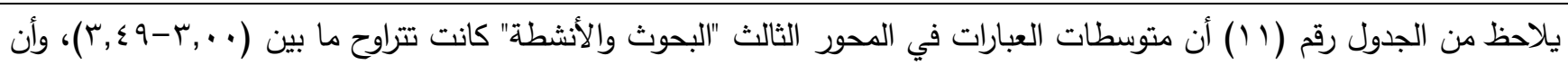

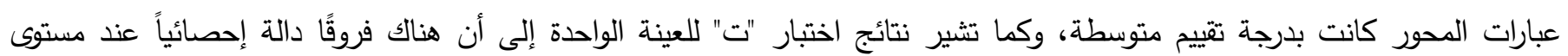
(a=0.05) بين عدد من المتوسطات الحسابية المحسوبة لكل فقرة على هذا المحور والمتوسط الفرضي، وهذا يعني أن الفروقات الظاهرة

بين هذه المتوسطات الحسابية للفترات والمتوسط المفترض (r) هي فروق حقيقية مؤثرة. بالنسبة للمحور الرابع: الخدمات الإثرافية والإدارية:

جدول رقم (r ا ): يوضح فقرات المحور الرابع من حيث قوة تأثيرها، كذلك يوضح نتائج اختبار "ت" لالالة هذه المتوسطات

\begin{tabular}{|c|c|c|c|c|c|}
\hline 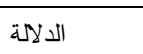 & $\mathrm{DF}$ & 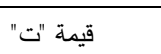 & المتوسط & العبارة & الرقم \\
\hline$\alpha=0.05$ & 91 & $\varepsilon, \ldots$ & $r, \leqslant 7$ & السياسات الإدارية للبرنامج واضحة ومحددة في رؤية ورسالة وأهداف القسم. & 1 \\
\hline$\alpha=0.05$ & 91 & $r, q 4$ & $r, \S)$ & يدير القسم أساتذة مختصين وذو خبرات عالية. & r \\
\hline$\alpha=0.05$ & 91 & r,IT & r, r & تبدي إدارة القسم واساتذته مرونة في تطبيق اللوائح والقوانين والأنظمة الخاصة بالطلبة. & r \\
\hline$\alpha=0.05$ & 91 & $r, r v$ & r, ro & تتعامل إدارة القسم واساتذته بطريقة ديمقراطية وحوارية في التعامل مع الطلبة. & $\varepsilon$ \\
\hline$\alpha=0.05$ & 91 & r,or & $r, r v$ & يسود الود والتفاهم في التعامل بين أساتذة القسم والطلبة. & $\circ$ \\
\hline$\alpha=0.92$ & 91 & $\cdot, 90-$ & r,१९ & يسهل القسم الإجراءات الإدارية الخاصة بمعاملات الطلبة مع الأقسام الأخرى. & 7 \\
\hline$\alpha=0.76$ & 91 & $\cdot, r \cdot$ & $r, \cdot r$ & عدد الطلبة في مجموعات الإرشاد الأكاديمي مناسبة بالنسبة لعدد الأساتذة. & v \\
\hline$\alpha=0.13$ & 91 & 1,0 & $r, 1 \wedge$ & الساعات المكتبية لكل أستاذ مقرر مناسب بالنسبة لعدد الطلبة لكل مجموعة. & $\wedge$ \\
\hline$\alpha=0.67$ & 91 & $\cdot, \varepsilon r-$ & r, 90 & أوقات الساعات المكتبية وساعات الإرشاد الأكاديمي مناسبة لأوقات الطلبة. & 9 \\
\hline$\alpha=0.23$ & 91 & 1,11 & $r, 1 \leq$ & يستثر الطلبة جيدا الساعات المكتبية التي يحددها الأساتذة لكل مقرر. & 1. \\
\hline$\alpha=0.23$ & 91 & 1,19 & $r, 1 \leqslant$ & يقدم الأساتذة خدمات جيدة في الساعات الأكاديمية. & 11 \\
\hline$\alpha=0.82$ & 91 & $\cdot, r t$ & $r, \cdot r$ & والساعي الأساتذة الفروق الفردية في التحصيل خلال لقاهم بالطلبة في الساعات المكتبية & ir \\
\hline$\alpha=0.05$ & 91 & r.O. & r, rA & يعمل الأساتذة على تقديم الايضاحات اللازمة والثرح الكافي لما يطلبه الطلبة خلال & ir \\
\hline
\end{tabular}

$\dot{i} \sim \dot{\dot{a}}\lrcorner \mid \wedge \wedge$ 


\begin{tabular}{|c|c|c|c|c|c|}
\hline & & & & الساعات المكتبية. & \\
\hline$\alpha=0.05$ & 91 & $1, \sqrt{ } 7$ & $r, r$. & يديدي الأساتذة مرونة في تحديد الساعات المكتبية بحيث تلاءم مختلف المجموعات التي & $1 \varepsilon$ \\
\hline$\alpha=0.05$ & 91 & $r, q \leq$ & r, ro & ليبلكي الأساتذة مرونة في مقابلة الطلبة خارج نطاق الساعات المكتبية إذا دعت الضرورة & 10 \\
\hline$\alpha=0.05$ & 91 & T,97 & r., & يبلتي أعضاء القسم الأخرين مرونة في إرشاد الطلبة ومساعدتهم على فهم المقررات التي & 17 \\
\hline
\end{tabular}

يلاحظ من الجدول رقم (r) ( أن متوسطات العبارات في المحور الرابع "الخدمات الإرشادية والإدارية" كانت تتراوح ما بين

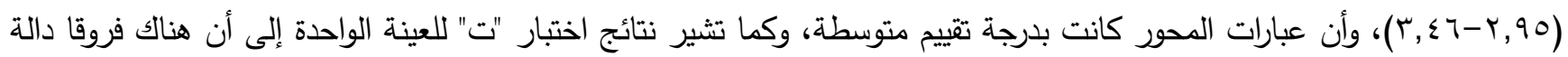
إحصائياً عند مستوى (a=0.05) بين عدد من المتوسطات الحسابية المحسوبة للفقرات على هذا المحور والمتوسط الفرضي، وهذات

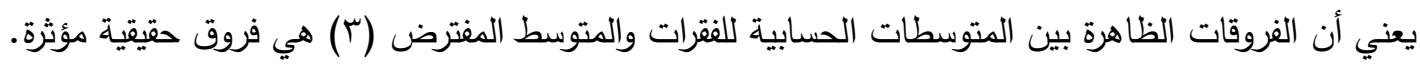
ويفسر الباحث ما توصل إليه من نتيجة حول السؤال الثالث من الدراسة حول تتييمهم للبرنامج أن هذه النتائج كانت طبيعية

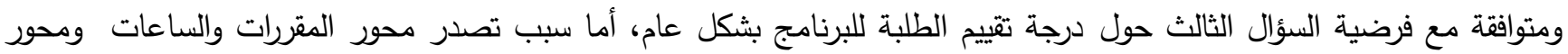
الخدمات الإرشادية والإدارية فذلك بسبب أهمية هذين المحورين للطلبة وملامستهما لحاجاتهم بشكل مباشر ، وأن نتيجة محور البحوث

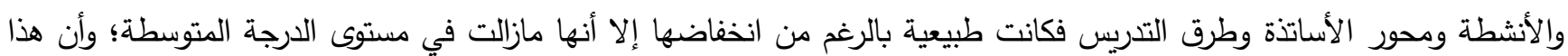
الانخفاض كان بسبب الضغط الذي يشعر به الطلبة من التكاليف المطلوبة من قبل الأساتذة، وتتقق هذه النتيجة مع ما توصلت إليه

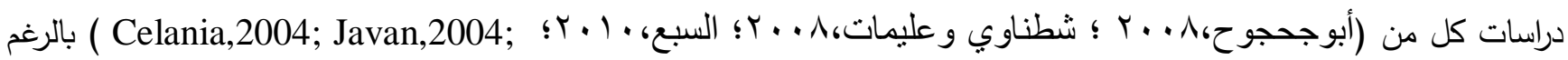

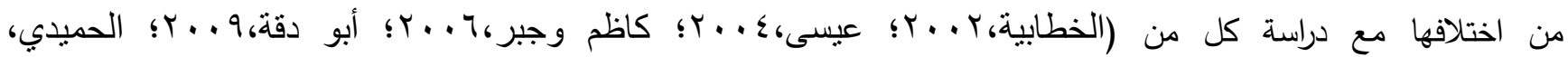

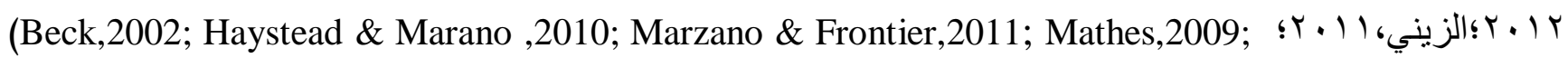
حول هذه المستوى وذلك بسبب اختلاف طبيعة العينة والأدوات المستخدمة في تلك الدراسات. ثانيا: نتائج السؤال الرابع

بالنسبة للسؤال الرابع في الدراسة الذي نص على: " هل تختلف درجة تقييم برنامج إعداد معلم اللغة الإنجليزية من وجهة نظر T- ) الطلبة في ضوء متغيرات الجنس والسنة الدراسية والمعدل التراكمي؟"، ولإجابة عن هذا السؤال فقد قام الباحث باستخدام اختبار (test للعينات المستقلة بالنسبة لمتغيري الجنس والسنة الدراسية، أما بالنسبة لمتغير المعدل التراكمي فقد قام الباحث باستخدام اختبار تحليل التباين الأحادي (One way ANOVA) وكانت النتائج كما يلي: بالنسبة للفروق في ضوء متغير الجنس فكانت النتائج كما يوضحها الجدول رقم (rآ):

\begin{tabular}{|c|c|c|c|c|c|c|}
\hline Sig & $\mathbf{T}$ & $\mathbf{F}$ & DF & Mean & المجموعة & المحور \\
\hline \multirow[t]{2}{*}{$\alpha=0.34$} & \multirow[t]{2}{*}{., $9 \leqslant-$} & \multirow[t]{2}{*}{$r, \leqslant r$} & \multirow[t]{2}{*}{9.} & $r, r \leq$ & ذكر & \multirow[t]{2}{*}{ المقررات والساعات } \\
\hline & & & & r, & أنثى & \\
\hline \multirow[t]{2}{*}{$\alpha=0.05$} & \multirow[t]{2}{*}{$r, .0$} & \multirow[t]{2}{*}{ ד,r } & \multirow[t]{2}{*}{9.} & r,YY & ذكر & \multirow[t]{2}{*}{ الأساتذة وطرق التدريس } \\
\hline & & & & $r, v q$ & أنثى & \\
\hline \multirow[t]{2}{*}{$\alpha=0.15$} & \multirow[t]{2}{*}{$1, \leq \leqslant$} & \multirow[t]{2}{*}{ V,rr } & \multirow[t]{2}{*}{9.} & $r, r \varepsilon$ & ذكر & \multirow[t]{2}{*}{ البحوث والأنثطة } \\
\hline & & & & $r, .0$ & أنثى & \\
\hline \multirow[t]{2}{*}{$\alpha=0.67$} & \multirow[t]{2}{*}{$\cdot, \leqslant 1$} & \multirow[t]{2}{*}{11,79} & \multirow[t]{2}{*}{9.} & r,rY & ذكر & \multirow[t]{2}{*}{ الخدمات الإشرافية } \\
\hline & & & & $r, I V$ & أنثى & \\
\hline \multirow[t]{2}{*}{$\alpha=0.22$} & \multirow[t]{2}{*}{ I, rr } & \multirow[t]{2}{*}{$\leqslant, \leqslant 9$} & \multirow[t]{2}{*}{9.} & r,Yr & ذكر & \multirow[t]{2}{*}{ المقياس بثكل عام } \\
\hline & & & & $r, .9$ & أنثى & \\
\hline
\end{tabular}




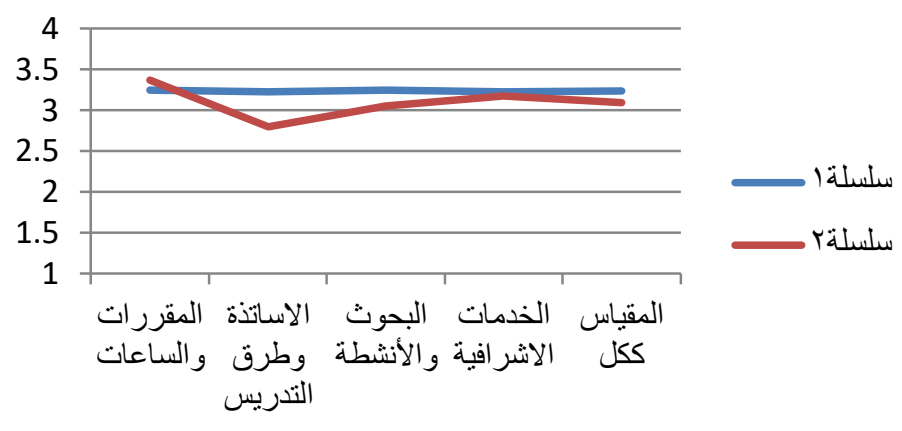

شكل رقم (ץ): يوضح الفروق في المتوسطات في ضوء متغير الجنس

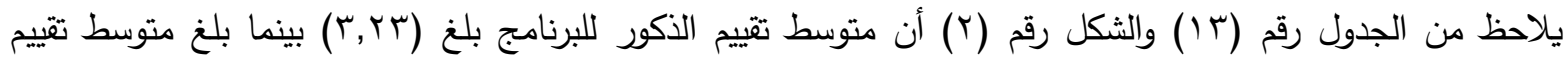

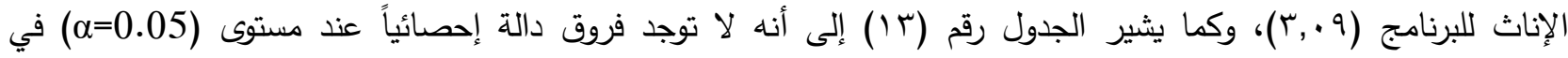

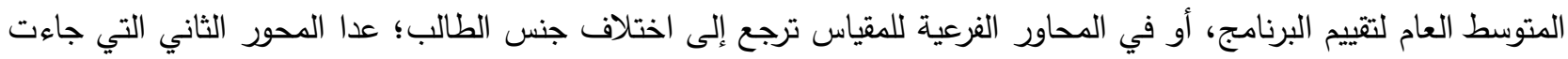

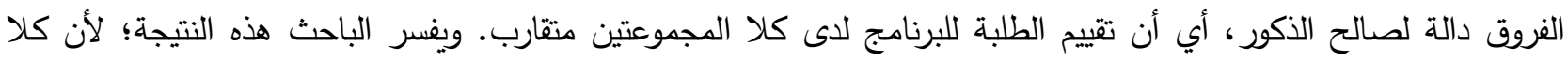
الجنسين من الطلبة يتعرضون لنفس الفرص والتحديات الأكاديمية لذلك جاءت آراؤهم متقاربة بالرغم من اختلاف مستوياتهم الدراسية في الكلية، إلا إنهم يواجهون نفس التحديات والصعوبات التي تتؤثر على تقدمهم العلمي وتحصيلهم الدراسي، كما أن خصائص المرحلة العمرية والمعرفية للطلبة في هذه المرحلة متقاربة والظروف التي يواجهونها متشابهة كما أن قدراتهم العقلية في

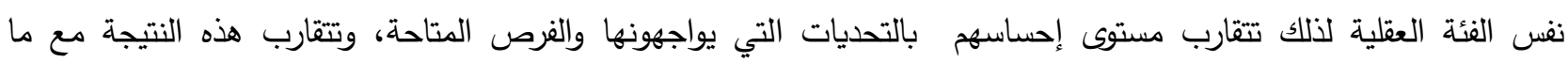

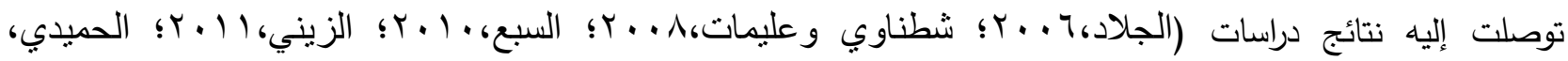

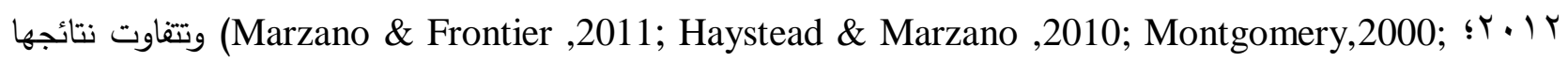

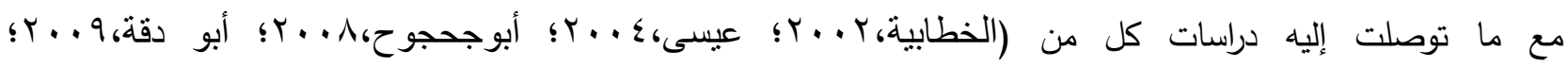

(Celania,2004; Mathes,2009; Javan,2004; Beck,2002;

بالنسبة للفروق في ضوء متفير السنة الاراسية فكانت النتائج كما يوضحها الجدول رقم ( ع ا):

جدول رقم (ء ) : يوضح نتائج اختبار (ت) للعينات المستقلة للمتغير السنة الدراسية

\begin{tabular}{|c|c|c|c|c|c|c|}
\hline Sig & $\mathbf{T}$ & $\mathbf{F}$ & DF & Mean & المجموعة & المحور \\
\hline \multirow[t]{2}{*}{$\alpha=0.52$} & \multirow{2}{*}{$\cdot, Y \leqslant-$} & \multirow{2}{*}{$1,1 \leq$} & \multirow[t]{2}{*}{9.} & $r, r_{0}$ & الثالثة & \multirow[t]{2}{*}{ المقررات والساعات } \\
\hline & & & & rr, & الرابعة & \\
\hline \multirow[t]{2}{*}{$\alpha=0.46$} & \multirow[t]{2}{*}{$\cdot, \mathrm{Vr}$} & \multirow[t]{2}{*}{1,01} & \multirow[t]{2}{*}{9.} & $r, i r$ & الثالثة & \multirow{2}{*}{ الأساتذة وطرق } \\
\hline & & & & $r, \cdot 1$ & الرابعة & \\
\hline \multirow{2}{*}{$\alpha=0.37$} & \multirow{2}{*}{$\cdot, 9 \cdot-$} & \multirow{2}{*}{$\varepsilon, 74$} & \multirow{2}{*}{9.} & $r, i r$ & الثالثة & \multirow{2}{*}{ البحوث والأنثطة } \\
\hline & & & & r,rr & الرابعة & \\
\hline \multirow[t]{2}{*}{$\alpha=0.87$} & \multirow[t]{2}{*}{$\cdot, 19-$} & \multirow[t]{2}{*}{$1,9 v$} & \multirow[t]{2}{*}{9.} & $r, r$. & الثالثة & \multirow[t]{2}{*}{ الخدمات الإثرافية } \\
\hline & & & & $r, r r$ & الرابعة & \\
\hline \multirow[t]{2}{*}{$\alpha=0.84$} & \multirow[t]{2}{*}{$\cdot, 19-$} & \multirow[t]{2}{*}{$\varepsilon,+1$} & \multirow[t]{2}{*}{9.} & $r, I V$ & الثالثة & \multirow[t]{2}{*}{ المقياس بثكل عام } \\
\hline & & & & $r, 19$ & الرابعة & \\
\hline
\end{tabular}




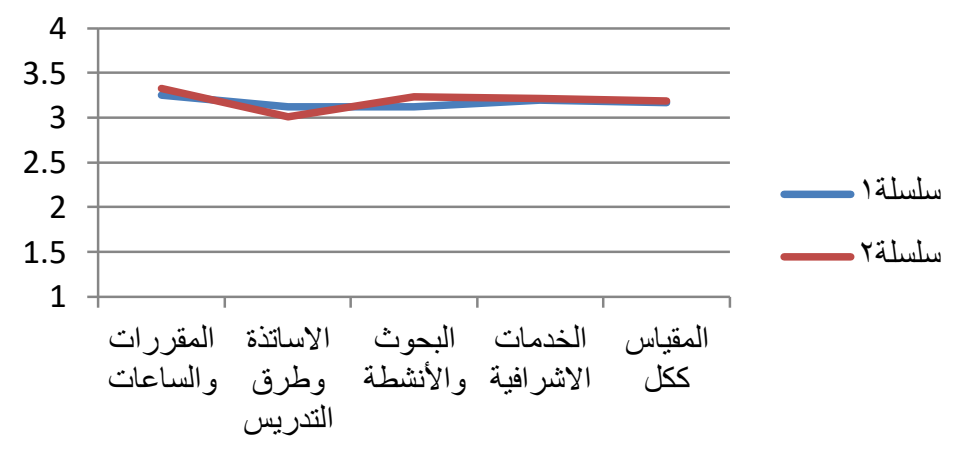

شكل رقم (ץ): يوضح الفروق في المتوسطات لمتغير السنة الدراسية

يلاحظ من الجدول رقم (ع ( ) والثكل رقم (Y) أن متوسط تقييم طلبة السنة الثالثة للبرنامج بلغ (Y) (Y) بينما بلغ متوسط

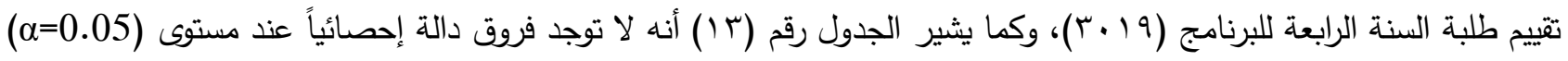
في المتوسط العام لتقييم البرنامج، أو في المحاور الفرعية للمقياس ترجع إلى اختلاف متغير السنة الرابعة، أي أن تقييم الطلبة

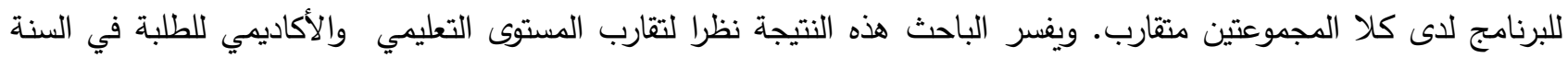
الثالثة والرابعة. لذلك جاءت آرائهم متقاربة بالرغم من اختلاف مستوياتهم الدراسية في الكلية، ولأنهم يواجهون نفس التحديات

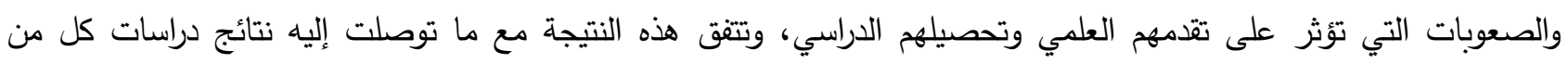

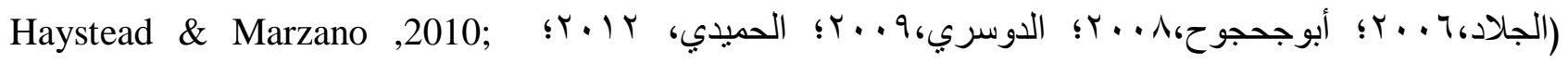
(Javan,2004; Montgomery,2000;

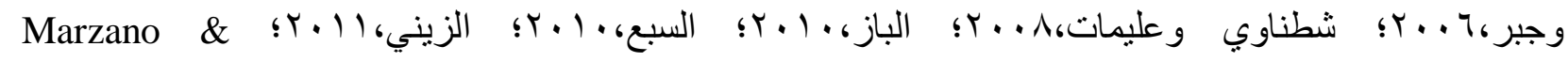

(Frontier,2011; Mathes,2009; Randy,1990;

بالنسبة للفروق في ضوء متفير المعدل التراكمي فكانت النتائج كما يوضحها الجدول رقم (0 ):

\begin{tabular}{|c|c|c|c|c|c|c|}
\hline Sig & Mean Squares & $\mathbf{F}$ & $\mathbf{D F}$ & Sum of squares & المجموعة & المحور \\
\hline \multirow[t]{2}{*}{$\alpha=0.22$} & 0.722 & \multirow[t]{2}{*}{1.50} & 3 & 1.34 & بين المجموعات & \multirow[t]{2}{*}{ المقررات والساعات } \\
\hline & 0.20 & & 87 & 25.98 & داخل المجموعات & \\
\hline \multirow[t]{2}{*}{$\alpha=0.90$} & 0.84 & \multirow[t]{2}{*}{0.08} & 3 & 0.26 & بين المجموعات & \multirow{2}{*}{ التدريس الأساتذة وطرق } \\
\hline & 0.20 & & 87 & 39.54 & داخل المجموعات & \\
\hline \multirow[t]{2}{*}{$\alpha=0.65$} & 2.45 & \multirow[t]{2}{*}{0.54} & 3 & 0.57 & بين المجموعات & \multirow[t]{2}{*}{ البحوث والأنثطة } \\
\hline & 0.39 & & 87 & 31.05 & داخل المجموعات & \\
\hline \multirow[t]{2}{*}{$\alpha=0.84$} & 0.84 & \multirow[t]{2}{*}{0.27} & 3 & $\mathbf{0 . 3 0}$ & بين المجموعات & \multirow[t]{2}{*}{ الذذمات الإشرافية } \\
\hline & 0.79 & & 87 & 32.76 & داخل المجموعات & \\
\hline \multirow[t]{2}{*}{$\alpha=0.82$} & 0.94 & \multirow[t]{2}{*}{0.29} & 3 & 0.24 & بين المجموعات & \multirow[t]{2}{*}{ المقياس بثكل عام } \\
\hline & 0.53 & & 87 & 23.78 & داخل المجموعات & \\
\hline
\end{tabular}

تشير نتائج اختبار تحليل التباين الأحادي في الجدول رقم (0 (1) إلى أنه لا توجد فروق دالة إحصائياً عند مستوى (a)=0.05)

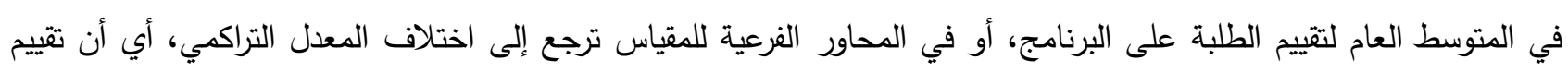
الطلبة للبرنامج لا يتأثر بمستوى معدلهم التراكمي، وأن مستوى تقييم الطلبة للبرنامج متقارب كونهم مجموعة متجانسة. ويفسر البرام

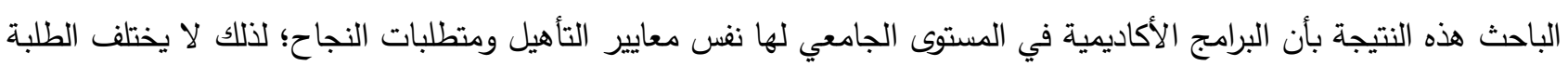
في المستويات التحصيلية المختلفة في تقييمهم للبرنامج نتيجة العبء الأكاديمي الناتج من كثر المتطلبات والمهام المطلوب من 


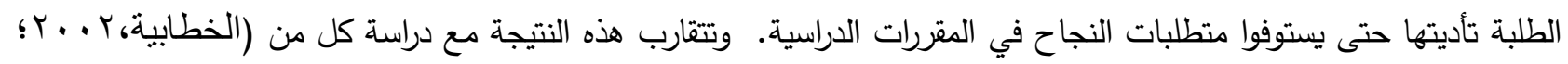

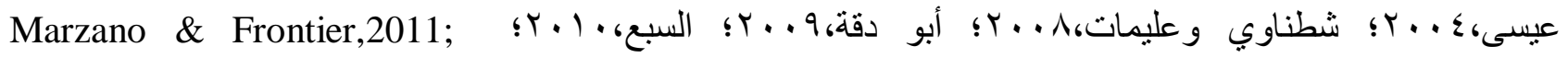
Mathes,2009; Montgomery,2000;

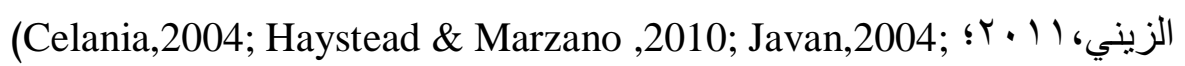

التوصيات:

$$
\text { توصي الدراسة الحالية بناء على النتائج التي تم التوصل إليها بما يلي: }
$$

ا ـ ضرورة مراجعة برنامج إعداد معلم اللغة الإنجليزية بكلية التربية بالرستاق وتحديثه باستمرار بشكل يشبع حاجات الطلبة

$$
\text { المعرفية والمهارية والتكنولوجية. }
$$

r. تطوير طرائق التدريس والتعلم بما يتماشى مع التطورات في الجانب التكنولوجي وخاصة التطبيقات على الأجهزة الذكية. r. تطوير الجانب التطبيقي في مهارات تعلم وممارسة اللغة وربطها بالأنشطة والبحوث الطلابية داخل وخارج الكلية.

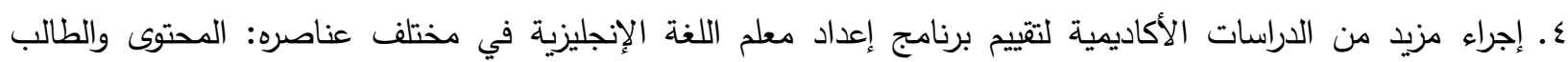
والمعلم وطراق التدريس والبحوث والأنشطة والخدمات الأكاديمية و حاجات المجتمع التربوي ومتغيرات التكنولوجيا والبرامج

الذكية.

ا. أبو جحجوح، ي.(1 . . (Y). تقويم برنامج إعداد معلم العلوم في كلية التربية بجامعة الأقصى، الجمعية السعودية للعلوم

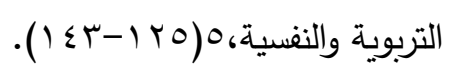

r. أبو دقة، س.(9 . . r). تقويم البرامج الأكاديمية بالجامعة الإسلامية بغزة من وجهة نظر الخريجين، مجلة الجامعة

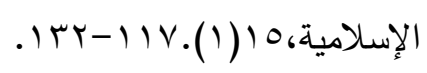

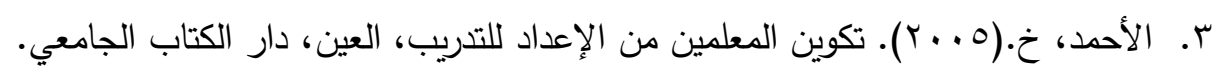

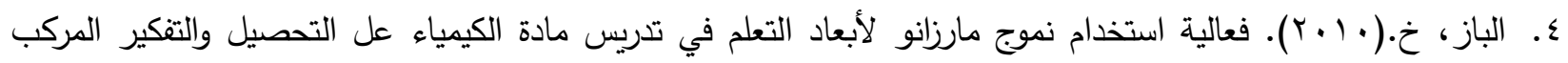

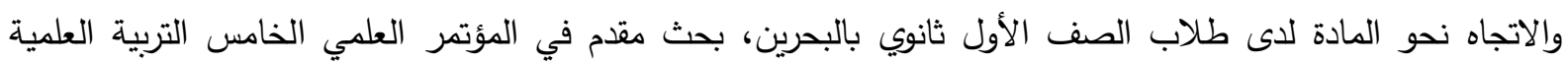

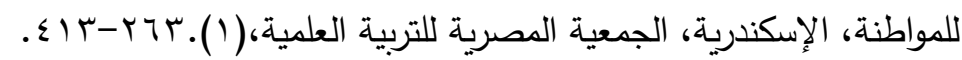

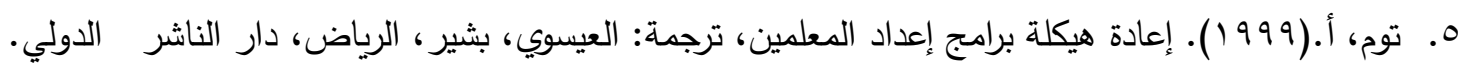

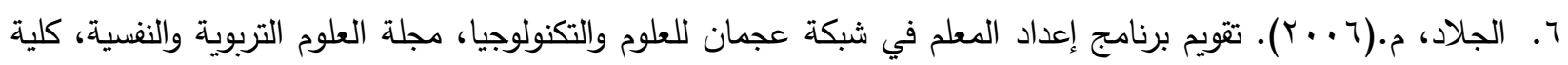

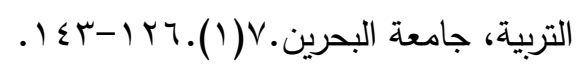

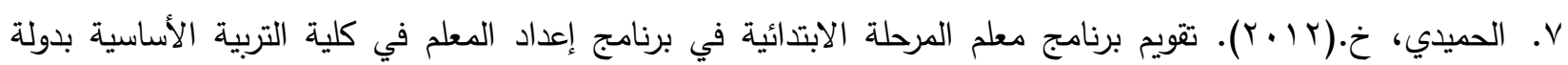

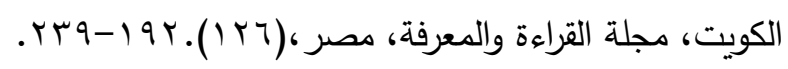

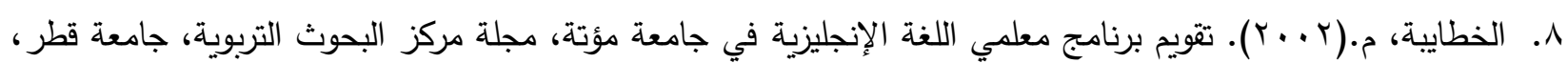

$$
. r \mid V-19 r_{6}(r) 111
$$

9. الدوسري، ر. (9 . . r). تقويم المعلم مقاربات جديدة وأساليب حديثة، دار كيوان للطباعة والنشر والتوزيع، سوريا.

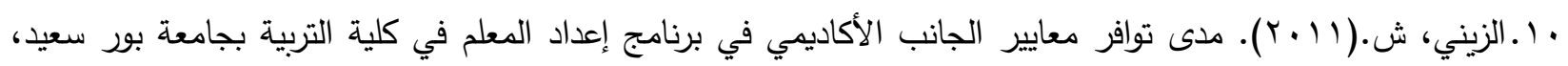

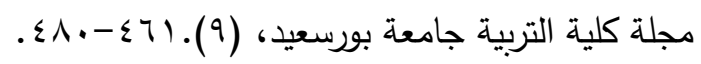




$$
\begin{aligned}
& \text { 1ا. السبع، س.(• ( • (). تقويم برنامج معلم اللغة العربية في كلية التربية بجامعة صنعاء في ضوء معايير الجودة الثاملة، }
\end{aligned}
$$

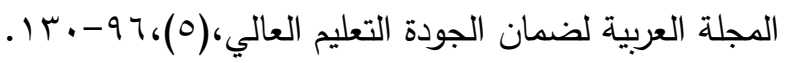

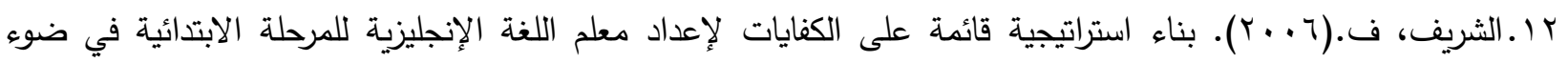

$$
\begin{aligned}
& \text { الاتجاهات العلمية الحديثة، رسالة دكتوراه غير منشورة، قسم المناهج وطرق التدريس، كلية التربية، جامعة أم القرى، مكة لإهـ } \\
& \text { المكرمة. }
\end{aligned}
$$

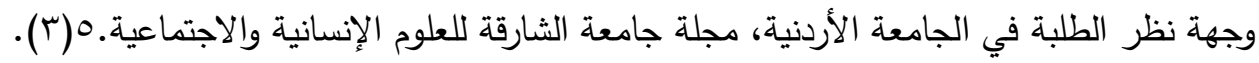

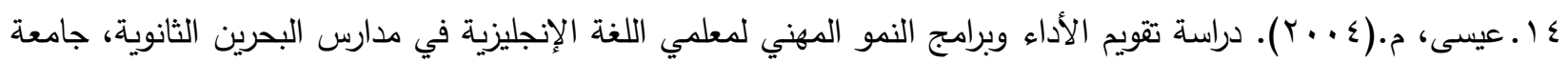

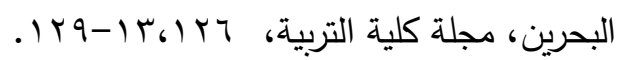

$$
\begin{aligned}
& \text { 1 ـفضل، ن.(99191). التطوير المهني لبرامج الإعداد التخصصي للمعلم دراسة حالة، المؤتمر العلمي الثاني، الجمعية }
\end{aligned}
$$

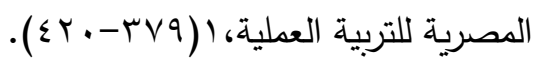

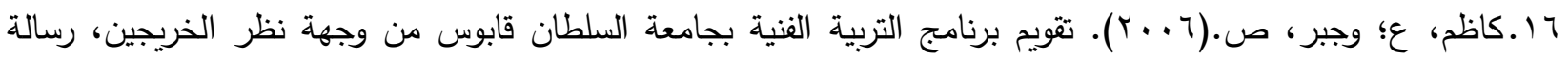

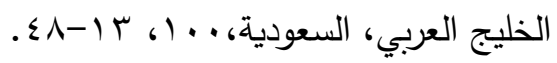

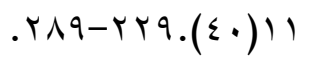

$$
\begin{aligned}
& \text { ثانياً: المراجع الأجنبية: }
\end{aligned}
$$

[1] C .Beck, (2002). Components of a good practicum placement, Student Teacher Perceptions http://www.findarticle-com/p/articles/miqa360lis - 200204/ai- nqou9695/print.

[2] E. Celania, (2004).A Study Of Iowa Second-Year Teacher's Perception Of The Iowa Teaching Standards And Implementation Of The Iowa Teacher's Quality Program. Dissertation Abstract International-A 65/02, P.357.

[3] H. Hallman \& H. Meineke. (2016). Addressing the Teaching of English Language Learners in the United States: A case Study of Teacher Educators' Response,Brock Education Journal, 26(1).68-82.

[4] M.W. Haystead \& R.J. Marzano, (2010) Final Report: A Second Year Evaluation Study of Promethean Active Classroom. Englewood, CO: Marzano Research Laboratory .

[5] M.H. Javan, (2004). Improving Pre-Service Elementary Teacher Education In The Islamic Republic Of Iran. Dissertation Abstract International-A64/10,P.3649.

[6] E. Lucero \& J. Scalante-Morales, (2018). English language teacher educator interactional styles: Heterogeneity and homogeneity in the ELTE classroom. HOW, 25(1), 11-31. https://doi.org/10.19183/how.25.1.358.

[7] M. Maizatulliza \& R.Kiely (2017). Students' Evaluation of their English Language Learning Experience, DINAMIKA ILMU,Vol. 17 No. 2, 2017, 205-222.

[8] R. J. Marzano, T. Frontier \& D. Livingston, (2011). Effective supervision: Supporting the art and science of teaching. Alexandria VA: ASCD.

[9] Mathes, Y. mickie. (2009). "Case Study in Assuring Quality University", A Workshop in the Conference of Standards accreditation in Arab World, visions and experiences, Almandine Almonawarah, Faculty of Education, Tibah University, in 18-20/5/2009.

[10] T. McGreal, (1988). Teacher Evaluation : Six Prescriptions for Success. Alexandria, VA : ASCD.

[11] B. Montgomery (2000). The Student and cooperating Teacher Relationship. Journal of Family and Consumer Science Education,18 (2). 7 - 15. 
[12] F. Randy ( 1990) " A comparison of the Attitudes of Lowa High School Teachers and principals Towers Teacher Evaluation and the Purposes of Teacher Evaluation" EDD ,Drake Univ, (DAI 51/09 A,P.2939).

[13] A. Saadi \& M . Saeed (2010) . Perceptions of Students, Educators and Principals about Quality Assurance of Elementary Teacher Education. Journal of Educational Research, 13:(1), p $92-104$.

[14] T. Schrier, (1994). Understanding the foreign language teacher education process. ADFL Bulletin, No (25).

[15] N. Vevere, (2009) . Analysis of the Quality Assurance System in the Higher Education Establishment . Journal of Business Management,14 (2), 108- 121. 


\title{
Estimation of English Language Teaching Programme at Rustaq College of Education from the English Speciality Students' Points of View
}

\section{Humood Abdullah Salim Al-Shukri}

\author{
Rustaq College of Education - Sultanate of Oman \\ humoud98.rus@cas.edu.om
}

\begin{abstract}
:
The study aims to estimate English Language Teaching programme at Rustaq College of Education from the English speciality students' points of View. For data collection, the researcher designed a questionnaire for evaluating the programme. The reliability and validity of the study tool has been tested, and the tool was found valid for the study. The reliability coefficient was $\alpha=0.95$. The validity was also tested. The study involved a sample of 92 of both third and fourth year English specialty students of the programme, 59 males and 33 females at Rustaq College of Education, distributed into the variables of gender, year of study and GPA.

The study results have shown that the evaluation of the students of the programme was average, as the general average of the evaluation was 3.18. As far as the order of factors is concerned, the courses and hours came first, the supervision and administrative factors came second, then the research and activities, and finally teachers and teaching methods, and the averages were (3.07 - 3.17 - 3.21 - 3.29) respectively. Moreover, the results have not indicated any significant differences pertinent to the variables gender, year of study or GPA. That is, there was a consensus among the students in the evaluation of the programme.
\end{abstract}

Keywords: Programme evaluation, English Language Teacher Training, Rustaq College of Education 